\title{
Level 2 processing for the imaging Fourier transform spectrometer GLORIA: derivation and validation of temperature and trace gas volume mixing ratios from calibrated dynamics mode spectra
}

\author{
J. Ungermann ${ }^{1}$, J. Blank ${ }^{1}$, M. Dick ${ }^{1}$, A. Ebersoldt ${ }^{2}$, F. Friedl-Vallon ${ }^{3}$, A. Giez ${ }^{4}$, T. Guggenmoser ${ }^{1, *}$, M. Höpfner ${ }^{3}$, \\ T. Jurkat ${ }^{5}$, M. Kaufmann ${ }^{1}$, S. Kaufmann ${ }^{5}$, A. Kleinert ${ }^{3}$, M. Krämer ${ }^{1}$, T. Latzko ${ }^{3}$, H. Oelhaf ${ }^{3}$, F. Olchewski ${ }^{6}$, \\ P. Preusse ${ }^{1}$, C. Rolf ${ }^{1}$, J. Schillings ${ }^{1}$, O. Suminska-Ebersoldt ${ }^{3}$, V. Tan ${ }^{1}$, N. Thomas ${ }^{1}$, C. Voigt ${ }^{5}$, A. Zahn $^{3}$, M. Zöger $^{4}$, \\ and M. Riese ${ }^{1}$ \\ ${ }^{1}$ Institut für Energie- und Klimaforschung - Stratosphäre (IEK-7), Forschungszentrum Jülich GmbH, Jülich, Germany \\ ${ }^{2}$ Institut für Prozessdatenverarbeitung und Elektronik, Karlsruher Institut für Technologie, Karlsruhe, Germany \\ ${ }^{3}$ Institut für Meteorologie und Klimaforschung, Karlsruher Institut für Technologie, Karlsruhe, Germany \\ ${ }^{4}$ Flugexperimente, Deutsches Zentrum für Luft- und Raumfahrt, Oberpfaffenhofen, Germany \\ ${ }^{5}$ Institut für Physik der Atmosphäre, Deutsches Zentrum für Luft- und Raumfahrt, Oberpfaffenhofen, Germany \\ ${ }^{6}$ Institute for Atmospheric and Environmental Research, University of Wuppertal, Wuppertal, Germany \\ *now at: European Space Agency, Noordwijk, the Netherlands
}

Correspondence to: J. Ungermann (j.ungermann@fz-juelich.de)

Received: 19 September 2014 - Published in Atmos. Meas. Tech. Discuss.: 2 December 2014

Revised: 29 March 2015 - Accepted: 24 May 2015 - Published: 17 June 2015

\begin{abstract}
The Gimballed Limb Observer for Radiance Imaging of the Atmosphere (GLORIA) is an airborne infrared limb imager combining a two-dimensional infrared detector with a Fourier transform spectrometer. It was operated aboard the new German Gulfstream G550 High Altitude LOng Range (HALO) research aircraft during the Transport And Composition in the upper Troposphere/lowermost Stratosphere (TACTS) and Earth System Model Validation (ESMVAL) campaigns in summer 2012.

This paper describes the retrieval of temperature and trace gas $\left(\mathrm{H}_{2} \mathrm{O}, \mathrm{O}_{3}, \mathrm{HNO}_{3}\right)$ volume mixing ratios from GLORIA dynamics mode spectra that are spectrally sampled every $0.625 \mathrm{~cm}^{-1}$. A total of 26 integrated spectral windows are employed in a joint fit to retrieve seven targets using consecutively a fast and an accurate tabulated radiative transfer model. Typical diagnostic quantities are provided including effects of uncertainties in the calibration and horizontal resolution along the line of sight. Simultaneous in situ observations by the Basic Halo Measurement and Sensor System (BAHAMAS), the Fast In-situ Stratospheric Hygrometer (FISH), an ozone detector named Fairo, and the Atmospheric chemical Ionization Mass Spectrometer (AIMS) allow a val-
\end{abstract}

idation of retrieved values for three flights in the upper troposphere/lowermost stratosphere region spanning polar and sub-tropical latitudes. A high correlation is achieved between the remote sensing and the in situ trace gas data, and discrepancies can to a large extent be attributed to differences in the probed air masses caused by different sampling characteristics of the instruments.

This 1-D processing of GLORIA dynamics mode spectra provides the basis for future tomographic inversions from circular and linear flight paths to better understand selected dynamical processes of the upper troposphere and lowermost stratosphere.

\section{Introduction}

The upper troposphere/lower stratosphere (UTLS) is a highly dynamic region, the composition of which is determined by the interaction of stirring and mixing processes with transport barriers. It exerts its influence on the whole climate system (e.g. Nakamura, 1996; Haynes and Shuckburgh, 2000; Solomon et al., 2007; Riese et al., 2012). In this region, 
the subtropical jet forms typically a barrier for tropospherestratosphere exchange, which can weaken in the presence of breaking Rossby waves and thus allow for isentropic transport (e.g. Chen, 1995; Berthet et al., 2007). Especially during summer, when the jet is weak, the UTLS over Europe consists of a cascade of small filaments (Postel and Hitchman, 1999; Ungermann et al., 2013; Gille et al., 2014).

Examining this region with airborne in situ instruments gives precise and accurate information on the trace gas distribution confined to the flight path but allows thus only for sketchy coverage. Using remote sensing instruments with a high vertical resolution such as limb sounders offers a much more complete spatial picture. Observing the atmosphere with limb sounders from space (e.g. Offermann et al., 1999; Hegglin et al., 2009; Gille et al., 2008; Fischer et al., 2008; Peevey et al., 2014) has greatly increased our knowledge of the dynamical and chemical structure of the atmosphere, but satellite-born instruments lack the vertical resolution to observe the strong vertical gradients occurring around the tropopause. Airborne limb sounders close the gap between in situ and space instruments and thus allow for the observation of small-scale structures such as the tropopause inversion layer (Birner, 2006; Riese et al., 2014).

The Gimballed Limb Observer for Radiance Imaging of the Atmosphere (GLORIA) is the first realisation of the limbimagining technique originally proposed for satellite applications (Riese et al., 2005; Friedl-Vallon et al., 2006). The instrument combines an imaging detector with a Fourier transform spectrometer. To operate on an aircraft, it is placed in a gimbal (a cardanic frame), which is used to stabilise the pointing against movements of the carrier and to adjust the viewing direction. It offers a high vertical resolution of down to $250 \mathrm{~m}$ and, in combination with tomographic measurement patterns, even the 3-D reconstruction of atmospheric structures is feasible (Kaufmann et al., 2015). GLORIA can be tuned between the highly spatial "dynamics mode" and the highly spectral "chemistry mode" resolution (see Sect. 2). GLORIA was first operated on the Geophysica research aircraft during the Esa Sounder Campaign (EsSenCe; Kaufmann et al., 2013) based in Kiruna, Sweden, in 2011 with a limited number of measured profiles. The first deployment with extended data coverage took place during the TACTS (Transport And Composition in the upper Troposphere/lower most Stratosphere) and ESMVal (Earth System Model Validation) campaigns in the High Altitude LOng Range (HALO) aircraft (a Gulfstream G550) in summer 2012.

This paper provides a complete picture of the 1-D level 2 processing of GLORIA "dynamics mode" data. It continues the work presented by Kaufmann et al. (2015) by also providing the important tropospheric tracer $\mathrm{H}_{2} \mathrm{O}$ with high sensitivity in the lower stratosphere. The selection of spectral regions has been greatly improved upon by incorporating new insights into instrument behaviour. Further, the accuracy of the retrievals has been improved by employing a more ac- curate radiative transfer model. Lastly, a detailed validation is presented that exploits the available in situ instrumentation aboard HALO. While the described 1-D retrievals are inaccurate in the presence of horizontal gradients (in contrast to the 3-D tomography of Kaufmann et al., 2015), they do not require dedicated flight patterns as tomography and can quickly provide an overview picture of the dynamic situation.

First, the instrument will be described followed by a description of the "dynamics mode" level 2 processor and the used configuration designated V1.00 for the GLORIA data processing. The paper proceeds by presenting the derived distributions of temperature and trace gas mixing ratios of $\mathrm{H}_{2} \mathrm{O}, \mathrm{O}_{3}$, and $\mathrm{HNO}_{3}$ from 7 to $15 \mathrm{~km}$ altitudes above northern Europe on 26 September 2012. After the discussion of systematic errors, the retrieved trace gas distributions are validated against simultaneous in situ observations on HALO during three flights in September 2012 covering polar, midlatitude, and subtropical regions.

\section{GLORIA instrument}

The GLORIA instrument is a Fourier transform spectrometer (FTS) with a HgCdTe infrared image detector array (cooled to an operating temperature of $50 \mathrm{~K}$ ) allowing to take up to 16384 spectra simultaneously. To reduce the read out time, only 6144 of these are currently used. The usable spectral coverage ranges from approximately 780 to $1400 \mathrm{~cm}^{-1}$ while the spectral sampling can be adjusted quite freely (see Table 1). During the TACTS and ESMVAL campaigns, two spectral sampling configurations were used: $0.625 \mathrm{~cm}^{-1}$ (dynamics mode) and $0.0625 \mathrm{~cm}^{-1}$ (chemistry mode). The detector has a fixed pixel pitch of $\approx 1.9 \operatorname{arcmin}\left(0.032^{\circ}\right)$, which corresponds to a vertical sampling of $\approx 140 \mathrm{~m}$ at a tangent point $5 \mathrm{~km}$ below flight altitude. GLORIA is mounted in a gimbal that, on the one hand, allows to counterpoise movements of the aircraft during the image acquisition and, on the other hand, to point the instrument at different azimuth angles covering slightly less than $90^{\circ}$. The latter enables 3-D tomographic retrievals where the same air mass is measured from multiple viewing angles (Ungermann et al., 2011; Kaufmann et al., 2015).

\section{Level 2 processing}

This section gives an overview over the level 2 processing of calibrated GLORIA dynamics mode spectra that were produced by the Python-based GLORIA level 0/level 1 processors named "gloripy". These processors transform the detector signals as a function of the interferometer sledge position to calibrated spectra (see Kleinert et al., 2014; Guggenmoser et al., 2014, for details). The level 2 processing by the Juelich Rapid Spectral Simulation Code V2 (JURASSIC2) and the JUelich Tomographic Inversion Library (JUTIL) software packages map the radiance values measured at different el- 
Table 1. Key instrument characteristics and properties (Friedl-Vallon et al., 2014).

\begin{tabular}{ll}
\hline Property & Value \\
\hline Detector array size & $256 \times 256$ pixels \\
Used detector array size & $48 \times 128$ pixels \\
Vertical sampling & $0.031^{\circ}$ \\
Horizontal sampling & $0.031^{\circ}$ \\
Aggregated horizontal coverage & $1.5^{\circ}\left(=48 \cdot 0.031^{\circ}\right)$ \\
Vertical spatial coverage & $-3.3^{\circ}$ to $0.8^{\circ}$ above horizon \\
Yaw pointing range & $45^{\circ}$ to $135^{\circ}$ \\
Pointing stability (vertical, $1 \sigma)$ & $0.012^{\circ}$ \\
Spectral coverage & $780 \mathrm{~cm}^{-1}$ to $1400 \mathrm{~cm}^{-1}$ \\
Spectral sampling & $0.0625 \mathrm{~cm}^{-1}$ to $0.625 \mathrm{~cm}^{-1}$ \\
Temporal sampling & $2 \mathrm{~s}(\approx 0.5 \mathrm{~km}) @ 0.0625 \mathrm{~cm}^{-1}$ spectral sampling \\
& $12.8 \mathrm{~s}(\approx 3.2 \mathrm{~km}) @ 0.625 \mathrm{~cm}^{-1}$ spectral sampling \\
\hline
\end{tabular}

evation angles (that is tangent altitudes) to the geophysical quantities of temperature, trace gas volume mixing ratios, and extinction values. This forms an ill-posed problem that is approximated by a well posed one by means of a Tikhonovtype regularisation (Tikhonov and Arsenin, 1977).

Let $\mathbf{F}: \mathbb{R}^{n} \longmapsto \mathbb{R}^{m}, n, m \in \mathbb{N}$, be a (forward) model that maps a discrete representation of the atmospheric state $\boldsymbol{x} \in$ $\mathbb{R}^{n}$ onto a set of radiances. The set of (imperfect) measurements is represented by a vector $\boldsymbol{y} \in \mathbb{R}^{m}$, and the assumed (prior) state of the atmosphere is given as $\boldsymbol{x}_{\mathrm{a}} \in \mathbb{R}^{n}$. Approximating the behaviour of the instrument noise by a Gaussian error covariance matrix $\mathbf{S}_{\epsilon} \in \mathbb{R}^{m \times m}$ and the vertical correlation of atmospheric state variables by a Gaussian covariance matrix $\mathbf{S}_{\mathrm{a}} \in \mathbb{R}^{n \times n}$, the original problem is approximated by a minimisation problem:

$$
\begin{aligned}
& J(\boldsymbol{x})=(\mathbf{F}(\boldsymbol{x})-\boldsymbol{y})^{\mathrm{T}} \mathbf{S}_{\epsilon}^{-1}(\mathbf{F}(\boldsymbol{x})-\boldsymbol{y}) \\
& +\left(\boldsymbol{x}-\boldsymbol{x}_{\mathrm{a}}\right)^{\mathrm{T}} \mathbf{S}_{\mathrm{a}}^{-1}\left(\boldsymbol{x}-\boldsymbol{x}_{\mathrm{a}}\right) \longrightarrow \min .
\end{aligned}
$$

This problem can be efficiently solved by quasi Newtontype methods, in our case a truncated conjugate gradientbased trust-region scheme (Ungermann, 2013).

\subsection{Retrieval targets}

The aim of the inversion is here to retrieve the primary targets of temperature, water vapour $\left(\mathrm{H}_{2} \mathrm{O}\right)$, ozone $\left(\mathrm{O}_{3}\right)$, and nitric acid $\left(\mathrm{HNO}_{3}\right)$. The secondary targets of carbon tetrachloride $\left(\mathrm{CCl}_{4}\right), \mathrm{CFC}-11$, and CFC-12 are retrieved to reduce systematic errors due to these background gases. The Antarctic flight requires additionally the derivation of chlorine nitrate $\left(\mathrm{ClONO}_{2}\right)$ due to the large encountered volume mixing ratios (VMRs). In addition, five different aerosol extinction profiles are retrieved, whereby each aerosol is applied only to a non-overlapping spectral region, and it is assumed that the optical characteristics of an aerosol remains approximately constant over its applicable wavenumber range (see Table 2). The listed integrated spectral windows (ISWs) used for the retrievals were selected by a genetic algorithm, which identifies the location and width of ISWs that maximises the information gain. The algorithm recombines initially randomly selected sets of ISWs preferring "good" sets and thus identifies a (nearly) optimal set much faster than a simple brute force search. Details are given by Blank (2013). The resulting windows were then modified to mitigate discovered instrument artefacts such as imperfectly compensated emissions of the outer window due to fast temperature changes. Generally, the volume mixing ratio of trace gases is retrieved. But for $\mathrm{H}_{2} \mathrm{O}$, the logarithm of the VMR is retrieved instead of the unmodified VMR. From a statistical point of view, this assumes that $\mathrm{H}_{2} \mathrm{O}$ VMRs follow a log-normal distribution, which can be justified in the target altitude range from radiosonde measurements (e.g. Schneider et al., 2006). A full list of atmospheric quantities taken into account in the retrieval is given in Table 4 .

The retrieval grid has a sampling distance of $125 \mathrm{~m}$ between the surface and $18 \mathrm{~km}$ altitude, from where on the sampling becomes increasingly sparse: 1 above $18 \mathrm{~km}, 2$ above $24 \mathrm{~km}$, and 4 above $30 \mathrm{~km}$, with $60 \mathrm{~km}$ being the highest altitude. All targets are retrieved up to $20 \mathrm{~km}$ altitude except for $\mathrm{O}_{3}$ and $\mathrm{HNO}_{3}$, which are retrieved up to $60 \mathrm{~km}$.

\subsection{Regularisation and model a priori data}

The inverse problem is inherently ill-posed and requires some additional constraints to provide physically meaningful results. The JUTIL software package supports several regularisation schemes. For the processing of the data presented here, Tikhonov regularisation was chosen in combination with a rather weak climatological weighting. This regularisation largely follows the evaluation of previous campaigns (e.g. Ungermann et al., 2012) with slight changes due to the different signal-to-noise characteristics of the GLORIA instrument. 
Table 2. A list of integrated spectral windows (ISW) employed and their spectral range. The last four columns shown the bias and SD of the band and monochromatic model compared to RFM.

\begin{tabular}{|c|c|c|c|c|c|c|}
\hline \multirow[b]{2}{*}{ ISW } & \multirow{2}{*}{$\begin{array}{l}\text { aerosol } \\
\text { index }\end{array}$} & \multirow[b]{2}{*}{ range $\left(\mathrm{cm}^{-1}\right)$} & \multicolumn{2}{|c|}{ band } & \multicolumn{2}{|c|}{ monochromatic } \\
\hline & & & bias $(\% o)$ & stddev $(\% o)$ & bias $(\% o)$ & stddev $(\% o)$ \\
\hline 0 & 0 & $790.625-791.250$ & 2.851 & 0.762 & 0.074 & 0.011 \\
\hline 1 & 0 & $791.875-792.500$ & -1.431 & 0.282 & 0.073 & 0.012 \\
\hline 2 & 0 & $793.125-793.750$ & -2.075 & 0.531 & 0.160 & 0.019 \\
\hline 3 & 0 & $794.375-795.000$ & 1.634 & 0.490 & 0.124 & 0.019 \\
\hline 4 & 0 & $795.625-796.250$ & -0.380 & 1.526 & 0.045 & 0.010 \\
\hline 5 & 0 & $796.875-797.500$ & -0.028 & 0.740 & -0.017 & 0.010 \\
\hline 6 & 0 & $798.125-798.750$ & 6.513 & 5.082 & -0.108 & 0.030 \\
\hline 7 & 0 & $799.375-799.375$ & 1.168 & 2.487 & -0.089 & 0.026 \\
\hline 8 & 1 & $845.000-849.375$ & -0.016 & 0.251 & 0.047 & 0.008 \\
\hline 9 & 1 & $850.000-854.375$ & -0.924 & 0.229 & -0.238 & 0.023 \\
\hline 10 & 1 & $855.000-859.375$ & -0.739 & 0.231 & -0.177 & 0.027 \\
\hline 11 & 2 & $883.750-888.125$ & -1.683 & 0.134 & 0.012 & 0.003 \\
\hline 12 & 2 & $892.500-896.250$ & -0.998 & 0.099 & -0.017 & 0.004 \\
\hline 13 & 2 & $900.000-903.125$ & -0.889 & 0.144 & 0.119 & 0.026 \\
\hline 14 & 2 & $918.750-923.125$ & 0.233 & 0.236 & 0.048 & 0.017 \\
\hline 15 & 3 & $956.875-962.500$ & -2.518 & 0.861 & 0.066 & 0.009 \\
\hline 16 & 3 & $980.000-984.375$ & -5.826 & 0.696 & 0.076 & 0.005 \\
\hline 17 & 3 & 992.500-997.500 & -2.909 & 0.406 & 0.055 & 0.004 \\
\hline 18 & 3 & $1000.625-1006.250$ & -0.696 & 0.337 & 0.023 & 0.004 \\
\hline 19 & 3 & $1010.000-1014.375$ & -0.243 & 0.179 & 0.003 & 0.002 \\
\hline 20 & 4 & $1388.125-1389.375$ & 3.001 & 1.910 & -0.001 & 0.013 \\
\hline 21 & 4 & $1390.000-1391.250$ & 1.102 & 0.812 & 0.012 & 0.024 \\
\hline 22 & 4 & $1391.875-1393.125$ & -0.264 & 0.545 & -0.002 & 0.036 \\
\hline 23 & 4 & $1393.750-1395.000$ & 0.391 & 0.476 & 0.001 & 0.004 \\
\hline 24 & 4 & $1395.625-1396.875$ & 0.973 & 1.418 & 0.016 & 0.019 \\
\hline 25 & 4 & $1397.500-1398.750$ & -0.932 & 0.401 & 0.005 & 0.022 \\
\hline
\end{tabular}

The precision matrix $\mathbf{S}_{\mathrm{a}}^{-1}$ is defined as

$\mathbf{S}_{\mathrm{a}}^{-1}=\left(\alpha_{0}\right)^{2} \mathbf{L}_{0}^{\mathrm{T}} \mathbf{L}_{0}+\left(\alpha_{1}\right)^{2} \mathbf{L}_{1}^{\mathrm{T}} \mathbf{L}_{1}+\left(\alpha_{2}\right)^{2} \mathbf{L}_{2}^{\mathrm{T}} \mathbf{L}_{2}$,

with $\alpha_{0}, \alpha_{1}, \alpha_{2} \in \mathbb{R}$ and $\mathbf{L}_{0}, \mathbf{L}_{1}, \mathbf{L}_{2} \in \mathbb{R}^{n \times n}$. The constraint can be separated into one constraint on the absolute value of retrieved target compared to a (climatological) mean weighted with its standard deviation (SD) and two smoothness criteria. The matrix $\mathbf{L}_{0}$ thus consists of a diagonal containing the reciprocal values of the SDs of the retrieved entities. The matrix $\mathbf{L}_{1}$ is a matrix to compute the first derivative of the vector $\boldsymbol{x}_{\boldsymbol{i}}$ by finite differences (it has -1 is on the main diagonal and 1 is on the first upper side diagonal, except for some rows that would take the difference of different quantities or non-neighbouring values). In addition each row of $\mathbf{L}_{1}$ is scaled with the reciprocal of the SD and $\sqrt{c_{\mathrm{q}} /\left(2 h_{i}\right)}$, with $c_{\mathrm{q}}$ being a quantity q specific correlation length and $h_{i}$ being the vertical distance between the elements of the vector that are being subtracted from each other (Steck and von Clarmann, 2001). Table 3 lists the empirically derived correlations lengths. $\mathbf{L}_{2}$ is set up similarly to $\mathbf{L}_{1}$ but with finite differences approximating the second derivative instead of the first. The sources for a priori values, background values, and SDs are listed in Table 4.
Table 3. Vertical correlation lengths employed for the regularisation.

\begin{tabular}{llll}
\hline parameter & value & parameter & value \\
\hline$c_{\text {aerosol0 }}$ & $640 \mathrm{~km}$ & $c_{\text {aerosol1 }}$ & $640 \mathrm{~km}$ \\
$c_{\text {aerosol2 }}$ & $640 \mathrm{~km}$ & $c_{\text {aerosol3 }}$ & $640 \mathrm{~km}$ \\
$c_{\text {aerosol4 }}$ & $10 \mathrm{~km}$ & $c_{\text {temperature }}$ & $0.9 \mathrm{~km}$ \\
$c_{\mathrm{CCl}_{4}}$ & $2 \mathrm{~km}$ & $c_{\mathrm{CFC}-11}$ & $8 \mathrm{~km}$ \\
$c_{\mathrm{CFC}-12}$ & $8 \mathrm{~km}$ & $c_{\mathrm{H}_{2} \mathrm{O}}$ & $5 \mathrm{~km}$ \\
$c_{\mathrm{HNO}_{3}}$ & $4 \mathrm{~km}$ & $c_{\mathrm{O}_{3}}$ & $40 \mathrm{~km}$ \\
\hline
\end{tabular}

Generally $\alpha_{0}$ is chosen to be 0.1 , which can be interpreted as an increase of the SD by a factor of 10 for regularisation of 0th order. The other $\alpha$ values are set to 1. For temperature and water vapour, the absolute value remains fully unconstrained. The vertical derivative computed by $\mathbf{L}_{1}$ of the profiles is constrained for all retrieval targets except for temperature. The log-normally distributed water vapour needs to be exempted here as the SD values given in the climatology were prepared assuming a normal distribution; in effect, no altitude-dependent scaling is performed for $\mathrm{H}_{2} \mathrm{O}$ (i.e. a SD of 1 is assumed for the log-normally distributed water vapour). 
Table 4. Sources for a priori or background values and associated SDs for atmospheric quantities. CLIM refers to the climatology by Remedios et al. (2007), ECMWF and WACCM to the respective models, and GLATTHOR refers to the profile derived by Glatthor et al. (2007), where the derived values are taken as 1-sigma uncertainty.

\begin{tabular}{|c|c|c|}
\hline quantity & value & SD \\
\hline temperature & ECMWF & $1 \mathrm{~K}$ \\
\hline pressure & ECMWF & $0.3 \%$ \\
\hline $\mathrm{CCl}_{4}$ & CLIM & CLIM \\
\hline $\mathrm{ClONO}_{2}$ & CLIM & CLIM \\
\hline $\mathrm{CH}_{4}$ & WACCM & CLIM \\
\hline $\mathrm{CO}_{2}^{+}$ & WACCM & CLIM \\
\hline CFC-F11 & CLIM & CLIM \\
\hline CFC-12 & CLIM & CLIM \\
\hline CFC-113 & CLIM & CLIM \\
\hline CFC-114 & CLIM & CLIM \\
\hline HCFC-22 & CLIM & CLIM \\
\hline $\mathrm{H}_{2} \mathrm{O}$ & $4 \mathrm{ppm}$ & - \\
\hline $\mathrm{HNO}_{3}$ & CLIM & CLIM \\
\hline $\mathrm{HNO}_{4}$ & CLIM & CLIM \\
\hline $\mathrm{N}_{2} \mathrm{O}$ & CLIM & CLIM \\
\hline $\mathrm{NH}_{3}$ & CLIM & CLIM \\
\hline $\mathrm{O}_{3}$ & CLIM & CLIM \\
\hline OCS & CLIM & CLIM \\
\hline $\mathrm{SF}_{6}$ & CLIM & CLIM \\
\hline $\mathrm{SO}_{2}$ & CLIM & CLIM \\
\hline PAN & 0 & GLATTHOR \\
\hline gain & 1 & $1 \%$ \\
\hline offset & 0 & $5 \mathrm{nW} \mathrm{cm}^{-2} \mathrm{sr}^{-1} \mathrm{~cm}^{-}$ \\
\hline elevation & 0 & $0.023^{\circ}$ \\
\hline
\end{tabular}

Lastly, the second vertical derivative of the temperature profile is constrained by the $\mathbf{L}_{2}$ matrix to produce temperature profiles with a smoother lapse rate.

As input to the retrieval, analysis data supplied by the European Centre for Medium-range Weather Forecasts (ECMWF) were used. The ECMWF data is available in six hour time steps with T799/L91 resolution, which corresponds to a horizontal resolution of $\approx 0.2^{\circ} \times 0.2^{\circ}$ and 91 levels in the vertical between the surface and $80 \mathrm{~km}$. For the well-mixed trace gases $\mathrm{CO}_{2}$ and $\mathrm{CH}_{4}$, data from the Whole Atmosphere Community Climate Model, version 4 (WACCM4; Garcia et al., 2007) were employed, mostly to capture the steady increase of $\mathrm{CO}_{2}$ in time that influences retrieved temperatures. The specific parametrisation used for the WACCM4 model run can be found in the publications of Lamarque et al. (2012) and Kunz et al. (2011).

\subsection{JURASSIC2 band radiative transfer model}

The JURASSIC2 band model is optimised for the fast simulation of measurements of coarse or moderate spectral resolution. It is thus suitable for the retrieval of large amounts of satellite data (e.g. Hoffmann and Alexander, 2009), but also for large-scale retrievals as posed by cross-section or tomographic retrievals (Ungermann et al., 2012; Kaufmann et al., 2015).

In a first step, the line-of-sight of a measurement is raytraced through the 1-D representation of the atmosphere (Hase and Höpfner, 1999). Here, also temperature gradients along the line-of-sight are taken into account. The horizontal temperature structure along the line-of-sight found in ECMWF model data is expressed for each altitude layer as difference to the temperature found horizontally at the closest tangent point location. This structure is then used to derive the actual temperature at a given position within an altitude layer in relation to the assumed or derived temperature at the tangent point location. The atmosphere is sampled along the line-of-sight in $5 \mathrm{~km}$ steps taking into account atmospheric refraction (Hase and Höpfner, 1999), forming a series of gas cells that are assumed to be homogeneous for simulation purposes.

In a second step, the emissivity and source function are computed for each gas cell and used to simulate the measured radiance. The band model uses tabulated optical path values for the typical ranges of atmospheric pressure, temperature, and number density values for the employed ISWs (which may be as small as a single spectral sample of GLORIA, but usually consist of the arithmetic mean of several neighbouring samples). The tables are generated by the reference forward model (RFM v4.3; Dudhia et al., 2002) using the current HITRAN2012 (Rothman et al., 2013) spectral database including all updates up to June 2014; the accuracy of the JURASSIC 2 model is here always taken in reference to the RFM. The tabulated optical path values are generated by convolving monochromatic emissivities with the instrument line shape (ILS) and conversion to optical path as a last step. This reversal of integration order makes this less exact, but several orders of magnitude faster than typical line-byline calculations. For fast radiative transfer calculations, the Curtis-Godson approximation (CGA; Curtis, 1952; Godson, 1953 ) and the emissivity growth approximation (EGA; Weinreb and Neuendorffer, 1973; Gordley and Russell, 1981) are employed. For both the CGA and EGA scheme, the optical path of the total column between the instrument up to and including the current homogeneous gas cell is computed to derive the local optical path only by forming the difference to the total optical path up to and including the previous homogeneous gas cell (which was determined in the previous step). A regression-based scheme may also be used to mitigate any bias introduced by the approximation, but is not needed for the retrieval presented in this paper. Here, simply the arithmetic mean of the values computed by the CGA and EGA methods is used (e.g. Marshall et al., 1994), as a later processing step corrects for any approximation errors introduced.

An important implementation detail is that the optical path was tabulated instead of the emissivity or transmissivity. As the optical path is much more linear with respect to num- 
ber density than the transmissivity (due to the highly nonlinear exponential function) this reduces the table size significantly for the same accuracy, and thereby reduces memory consumption and increases processing speed.

One ray is computed for each row of the detector. In a second step, the computed radiances are convolved with a fieldof-view function of the instrument determined from laboratory measurements compensating for optical and electronic effects. Using additional intermediate rays did not change the retrieval results or diagnostics significantly.

The model code uses a tool based on C++ operator overloading to provide analytically correct derivatives with respect to all input parameters with minimal computational overhead (Lotz et al., 2012).

\subsection{JURASSIC2 monochromatic radiative transfer model}

A new addition to JURASSIC2 is a monochromatic model that serves as a fast reference model. To be rather fast and accurate without becoming too complicated, it uses tabulated extinction cross-sections values on a fine spectral grid. This is considerably faster than actual line-by-line calculations for the spectral regions and emitters used in our retrievals. It is similar in purpose and design to the HIRDLS intermediate reference model (Francis et al., 2006). The spectral grid is configurable but currently uses a sampling of $0.002 \mathrm{~cm}^{-1}$, which is sufficient to resolve individual lines.

The ray tracing and field of view are computed in the same way as for the band model so that the same homogeneous gas cells are used in the computation. However, it is feasible to sample the atmosphere on different grids or use CurtisGodson means to combine neighbouring samples to larger cells in order to reduce simulation time. In contrast to the band model, the monochromatic model directly computes the emissivity for the local homogeneous gas cells and does not rely on an emissivity growth approximation.

To retain a high accuracy, the extinction cross-sections are not simply linearly interpolated as in the band model, but cubic splines are used. The spline coefficients are not precomputed, but generated on the fly using local information only to reduce memory consumption and bandwidth. That means that in a first step for each of the four pressure values surrounding the target pressure, a six point cubic spline interpolation in temperature is performed. Afterwards, the final value is derived from the previously computed four extinction values by means of a four point cubic spline interpolation in pressure. The boundary condition for each cubic spline is that the second derivative should be zero. The pressure log-linear grid uses 42 points between 1017 and $0.0103181 \mathrm{hPa}$, while temperature is regularly sampled in $5 \mathrm{~K}$ steps between 100 and $400 \mathrm{~K}$. It thus uses the same pressure and temperature grid as the band model. To reduce memory consumption, only extinction cross-sections for required temperature and pressure values are read into memory ondemand.

Continua and other smooth functions like the Planck function required in further computations are sampled on a $0.256 \mathrm{~cm}^{-1}$ wavenumber grid and are linearly interpolated in between. This greatly increases computation speed with no noticeable degradation of accuracy, especially with respect to the water vapour continua (MT_CKD version 2.5.2; Mlawer et al., 2012). By computing simulated radiances for the retrieved atmospheres of one flight with both JURASSIC2 models and RFM, the error of the band and the monochromatic model can be estimated (see Table 2). To provide only a comparison of the radiative transport and not the ray tracing, RFM was only used to compute the spectrally resolved emissivities of all homogeneous gas cells involved. Larger differences found in previous comparisons (Ungermann et al., 2012; Griessbach et al., 2013) are largely attributable to the different ray tracing schemes and differences in the interpolation of aerosol/extinction (linear compared to log-linear). Typically, the error of the band model increases with decreasing tangent point altitude.

The monochromatic model code was also designed to provide analytically correct derivatives by means of algorithmic differentiation. This allows the model to be used for validation of Jacobian matrices and retrievals. While it could be tuned to be much faster (coarser tables, less accurate interpolation, etc.), its primary purpose is to be highly accurate with respect to the (even slower) RFM used for table computation. However, as the campaign data set comprised of 62960 measured profiles is comparatively small (at least compared to typical satellite experiments), it is feasible to process it in 1-D using the monochromatic model. The retrieval result derived from the band model is used as initial guess for the monochromatic model, thereby reducing the number of required iterations to $\approx 3$ down from $\approx 10$ on average, whereby only the first iteration changes the result significantly. Using the more accurate model removes a bias in retrieved trace gases, which is most notable for $\mathrm{H}_{2} \mathrm{O}(\approx-6 \%)$ and $\mathrm{HNO}_{3}$ $(\approx 2 \%)$.

\subsection{Error analysis}

The errors of the retrieved quantities are analysed using a linear approximation (Rodgers, 2000), which can be expressed in the same notation introduced in the beginning of Sect. 3:

$\boldsymbol{x}_{\mathrm{f}}=\mathbf{A} \boldsymbol{x}_{\mathrm{t}}+(\mathbf{I}-\mathbf{A}) \boldsymbol{x}_{\mathrm{a}}+\mathbf{G} \boldsymbol{\epsilon}$.

The retrieval result $\boldsymbol{x}_{\mathrm{f}} \in \mathbb{R}^{n}$ is the sum of the true atmospheric state $\boldsymbol{x}_{\mathrm{t}} \in \mathbb{R}^{n}$ smoothed by the averaging kernel matrix $\mathbf{A} \in$ $\mathbb{R}^{n \times n}$, the a priori influence, and measurement errors $\epsilon \in \mathbb{R}^{m}$. Whereby

$\mathbf{G}=\left(\mathbf{S}_{\mathrm{a}}^{-1}+\mathbf{F}^{\prime}\left(\boldsymbol{x}_{\mathrm{f}}\right)^{\mathrm{T}} \mathbf{S}_{\epsilon}^{-1} \mathbf{F}^{\prime}\left(\boldsymbol{x}_{\mathrm{f}}\right)\right)^{-1} \mathbf{F}^{\prime}\left(\boldsymbol{x}_{\mathrm{f}}\right)^{\mathrm{T}} \mathbf{S}_{\epsilon}^{-1}$ 
and

$\mathbf{A}=\mathbf{G F}^{\prime}\left(\boldsymbol{x}_{\mathrm{f}}\right)^{\mathrm{T}}$,

where $\mathbf{F}^{\prime}\left(\boldsymbol{x}_{\mathrm{f}}\right)$ is the first derivative (Jacobian matrix) of the forward model $\mathbf{F}$ evaluated at the retrieval result $\boldsymbol{x}_{\mathrm{f}}$.

Given a covariance matrix $\mathbf{S} \in \mathbb{R}^{m \times m}$ describing the effect of an arbitrary error source on the measurements, the gain matrix $\mathbf{G}$ can be used to linearly estimate a covariance matrix describing the effect of this error source on the retrieval result as $\mathbf{G}^{\mathrm{T}} \mathbf{S G}$. Such a covariance matrix can be readily assembled at least approximately for many systematic error sources using SDs and a reasonable vertical correlation length using an auto-regressive approach (Rodgers, 2000). We distinguish between random errors stemming from measurement noise and other, usually systematic, error sources. The measurement noise is taken from theoretical estimates given by Friedl-Vallon et al. (2014). The characterisation of actual noise figures is still in progress; however, initial results indicate that the theoretically predicted values are sufficiently accurate for an error estimation. For ISWs covering several samples, the assumed noise is divided by the square root of the number of spectral samples. In addition, a fixed relative noise component of $0.1 \%$ is assumed for all ISWs.

The error estimate stemming from the noise error source is given as precision value. The errors stemming from misrepresented background gases, uncertainties in spectral line characterisation (taken to be $5 \%$ under the assumption that, statistically, some errors in individual line parameters cancel each other out), uncertainties in instrument attitude, and calibration errors are summed up under the label accuracy. It is assumed that gain and offset errors are spatially uncorrelated, but spectrally fully correlated (in the absence of a better characterisation, this provides a worse error estimate than assuming no spectral correlation).

The sum over each row of the averaging kernel matrix $\mathbf{A}$ is supplied as measurement contribution. The full width at half max of each row is also computed using linear interpolation to provide a measure of the vertical resolution. The smoothing error is not given, as the underlying covariance matrix $\mathbf{S}_{\mathrm{a}}$ describing the prior atmospheric state is far from being accurate in an optimal estimation sense. Still, the vertical resolution and measurement contribution can be used to gain insight into the quality of the data. Additionally, the horizontal resolution along the line-of-sight is supplied, which can be derived by generating a special averaging kernel matrix mapping a 2-D state of the atmosphere along the lineof-sight onto the 1-D retrieval result by multiplying the gain matrix $\mathbf{G}$ with a 2-D Jacobian matrix of the forward model with respect to a 2-D representation of the retrieved volume (e.g. von Clarmann et al., 2009; Ungermann et al., 2011).

As the logarithm of $\mathrm{H}_{2} \mathrm{O}$ VMRs is retrieved, the error analysis also supplies variances with respect to the logarithm. This is somewhat problematic, as the log-normal distribution in VMR space is biased, so that the mean value depends on the assumed SD. To remove this dependency, the median in
VMR space is given instead of the mean; using $\mathrm{q}_{\log }$ as the retrieved logarithmic VMR and $s_{\log }$ as an associated SD, the conversion from log-to VMR-space is performed with these formulae:

$$
\begin{aligned}
& \mathrm{q}_{\mathrm{VMR}}=\exp \left(\mathrm{q}_{\log }\right) \\
& s_{\mathrm{VMR}}=\exp \left(\mathrm{q}_{\log }\right) \sqrt{\exp \left(s_{\log }^{2}\right)-1} .
\end{aligned}
$$

\section{The TACTS and ESMVal campaigns}

The TACTS and ESMVal campaigns using the new German HALO aircraft took place in August and September 2012. GLORIA was deployed during all scientific flights, and it was operational during all but one short flight. The TACTS campaign focused on the UTLS of the extratropics and the transition to the tropics, with the main scientific objective to quantify the change of composition of the UTLS between summer and autumn. Most flights took place over Europe with several additional flights to Cape Verde including stops on the island. ESMVal focused on delivering meridional transects covering as many latitudes as possible to generate a comprehensive data set with the purpose of validation and enhancement of chemistry-climate models.

HALO flight paths of all campaign flights are shown in Fig. 1. Combining both campaigns, a broad geographic region was covered: from the Spitsbergen islands at $80^{\circ} \mathrm{N}$ down to close to Antarctica at $65^{\circ} \mathrm{S}$, and from Cape Verde at $23.6^{\circ} \mathrm{W}$ to the Maldives at $73.5^{\circ}$ E. GLORIA took 62960 spectrally resolved images during the campaigns, consisting of 386.8 million spectra covering a horizontal path of $\approx$ $66000 \mathrm{~km}$. Of these, only a small subset of several thousand profiles has currently been processed. The tangent points of profiles preliminary retrieved using the dynamics mode processor are shown in Fig. 1. In addition, first 3-D tomographic retrievals have been presented by Kaufmann et al. (2015).

The current state of level 0 and level 1 processing allows three flights to be processed with good confidence in the results, the flight towards Antarctica on 13 September 2012, the flight towards Spitsbergen on 23 September 2012, and a flight around the North Sea and the British Isles on 26 September 2012. Only this last flight is shown as an example, but data for all three flights are currently available on the HALO database (2014), where also further flights will be published as soon as they are available. Only profiles of these flights that measure at a yaw angle of $89^{\circ}$ and move the sled in forward direction have been processed.

\subsection{In situ instrumentation}

The HALO aircraft carried many different scientific instruments during the campaigns. Several of these measure the same quantities as GLORIA. Four of these are used for the validation of retrieved primary targets. 


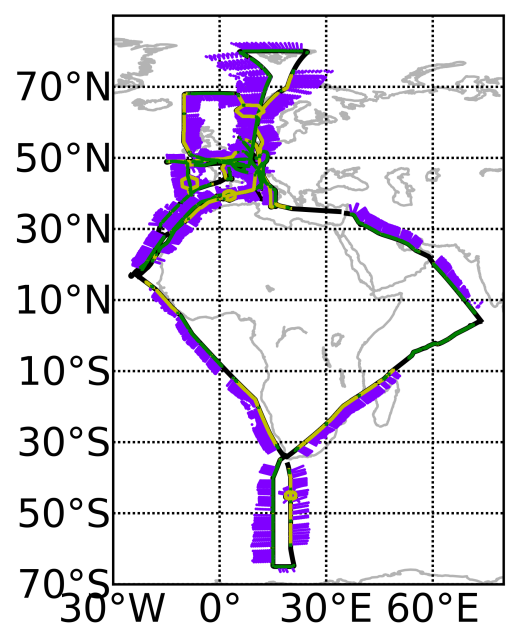

Figure 1. Overview over the flights performed during TACTS and ESMVAL. The flight paths are marked as black lines. Atmosphere measurements of GLORIA are overlayed in dark and light green for chemistry and dynamics mode, respectively. The tangent points of preliminarily processed profiles are shown in blue.

The airborne Fast In-situ Stratospheric Hygrometer (FISH) measures water vapour between 1 and 1000 ppmv. The measurement principle is based on Lyman- $\alpha$ photofragment fluorescence, which enables the possibility to measure low concentrations accurately. The instrument is regularly calibrated against a reference frost point hygrometer (MBW DP30) and has an accuracy of $\pm 7 \%+0.3 \mathrm{ppmv}$ (Zöger et al., 1999; Schiller et al., 2008). The FISH hygrometer is well established and was deployed on various aircraft campaigns as well as on both laboratory intercomparison campaigns AquaVit in 2007 (Fahey et al., 2014) and AquaVit II in 2013, and also on the aircraft intercomparison MACPEX in 2011 (Rollins et al., 2014).

The HALO Atmospheric chemical Ionization Mass Spectrometer (AIMS) measures $\mathrm{HNO}_{3}$ and other trace gases like $\mathrm{HCl}, \mathrm{ClONO}_{2}$, and $\mathrm{SO}_{2}$ in the UTLS region (Jurkat et al., 2014; Voigt et al., 2014). In the flow reactor, these trace gases react selectively with $\mathrm{SF}_{5}^{-}$ions via fluoride transfer (Jurkat et al., 2010; Voigt et al., 2010), and the resultant product ions are detected with a quadrupole mass spectrometer. The instrument is calibrated in flight using defined concentrations of nitric acid supplied by a nitric acid permeation oven, in total yielding an instrumental uncertainty of $25 \%$ for $\mathrm{HNO}_{3}$ at a temporal resolution of $1 \mathrm{~Hz}$. Successful measurements have been performed during all TACTS/ESMVal flights. On 23 September 2012, AIMS was operated in the water vapour mode (Kaufmann et al., 2014).

A light-weight $(14.5 \mathrm{~kg})$ instrument (named Fairo) for measuring ozone $\left(\mathrm{O}_{3}\right)$ with high accuracy $(2 \%)$ and high measurement speed $(10 \mathrm{~Hz})$ was developed for the use aboard HALO. It combines a dual-beam UV photometer with an UV-LED as light source and a dry chemiluminescence de- tector (Zahn et al., 2012). The performance of Fairo was excellent during all 13 flights of TACTS/ESMVal.

The Basic Halo Measurement And sensor System (BAHAMAS) consists of a powerful data acquisition system which monitors different interfaces of the aircraft avionic systems as well as a suite of instruments belonging to the system itself (Krautstrunk and Giez, 2012). These additional sensors allow for a precise determination of basic meteorological parameters like pressure, temperature, humidity and the 3-D wind vector. The temperature measurement on HALO is based on the total air temperature (TAT) method using a separate inlet (Goodrich Aerospace, formerly Rosemount, BW102) in combination with an open wire PT100 element. Two of these sensors are mounted on the aircraft nose in order to provide redundancy in the data. The TAT method and a respective error analysis are described by Bange et al. (2013). Since the calibration accuracy for the sensor element is better than $0.1 \mathrm{~K}$ between -70 and $+50^{\circ} \mathrm{C}$ the overall error in the aircraft temperature measurement is $0.5 \mathrm{~K}$. A Rosemount 858 flow angle sensor is used to measure the 3-D airflow as well as the static and dynamic pressure at aircraft level. The probe and the respective pressure sensors are mounted on a noseboom in order to reduce the influence of the aircraft fuselage on the measurement. However, since the pressure at the tip of the noseboom is still subject to an aircraft-induced perturbation, the exact measurement of static pressure on HALO requires an extensive in flight calibration. The flight test is described by Giez (2012) and demonstrates a $0.3 \mathrm{hPa}$ accuracy in the static pressure measurement (including a $0.1 \mathrm{hPa}$ calibration accuracy for the pressure sensor).

\subsection{Flight on 26 September 2012}

The last flight of the campaigns took place on 26 September 2012 starting from Oberpfaffenhofen, Germany, and ending at the same site. The flight path is shown in Fig. 2. A large hexagonal flight pattern over Norway will allow a tomographic evaluation of measurements in future work. Except for the beginning and end, the aircraft was nearly always within the lowermost stratosphere, allowing for the measurement of the tongue of UTLS air stretching in southwest/north-east direction in the trough between two crests of breaking Rossby waves. The potential vorticity contours within this air mass follow mostly this direction which usually indicates that trace gas filaments are similarly oriented. In this fashion, the direction of the lines of sight is roughly aligned with filamentary structures except for the second, northward-bound leg of the flight.

An example of a spectrum is shown in Fig. 3. The ISWs used can mostly be fitted within expected ranges with the exception of the vicinity of the strong line of the $\mathrm{CO}_{2}$ Q-branch at $792 \mathrm{~cm}^{-1}$, where the discrepancy between measurement and simulation often surpasses the threshold value for noise. The cause of this is likely an instrument artefact under in- 


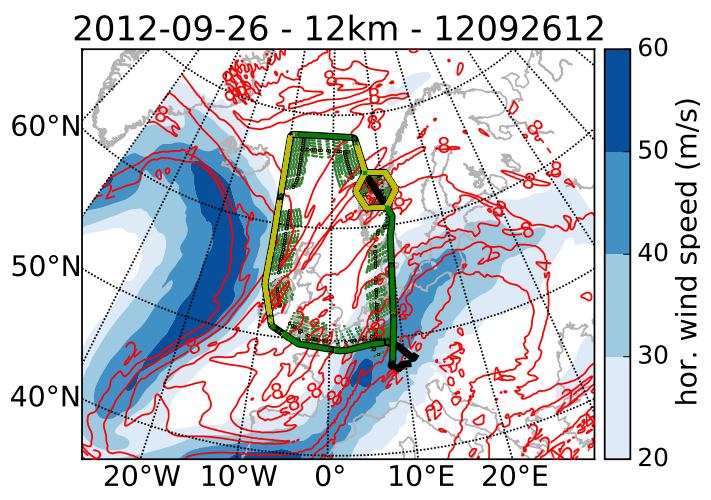

Figure 2. The synoptic situation during the flight of 26 September 2012. The flight path is marked as black line, the flight direction is clock-wise. Atmospheric measurements of GLORIA are overlayed in green and yellow for chemistry and dynamics mode, respectively. The tangent points of processed profiles are shown in green, where the tangent point vertically closest to $12 \mathrm{~km}$ is highlighted in yellow. Isolines of potential vorticity are shown in red. Wind speeds are shown as contour surfaces in blue shades. The meteorological data is taken from the ECMWF model state of 26 September 2012, 12:00 UTC.

vestigation that introduces spatially and spectrally correlated noise in the vicinity of strong spectral features. The discrepancy in the wavenumber range between 1100 and $1360 \mathrm{~cm}^{-1}$ is caused by $\mathrm{N}_{2} \mathrm{O}$ and to a lesser extent by $\mathrm{CH}_{4}$ that are both not retrieved. The wavenumber range around $830 \mathrm{~cm}^{-1}$ is influenced significantly by the optical properties of the spectrometer window. These optical properties vary quickly compared to the frequency of calibration measurements and, consequently, the affected wavenumber range had to be excluded from the retrieval ISWs.

The most important error sources for the primary retrieval targets are depicted in Fig. 4. To mitigate the impact of filamentary structures, an averaged error profile is shown. Obviously, the remaining uncertainty of elevation angle knowledge is the largest contributor to temperature and $\mathrm{H}_{2} \mathrm{O}$ accuracy at lower altitudes. Gain and offset are the most important remaining contributors to accuracy followed by relevant spectroscopic terms and $\mathrm{CO}_{2}$. The error introduced by uncertainty of background $\mathrm{CO}_{2}$ VMRs is part of the motivation for the use of WACCM4 data, which capture the general increase and also seasonal variations better than the Remedios climatology (Remedios et al., 2007).

The averaging kernels have been diagnosed to provide measurement contribution and vertical resolution (Fig. 5). Due to the nature of the regularisation employed, the measurement contribution is very close to 1 over the full altitude range, implying that the retrieval results are not biased in absolute value by the regularisation. The vertical resolution is consistently better than $500 \mathrm{~m}$ and as low as $250 \mathrm{~m}$ close to the aircraft for the trace gases and on the order of $1 \mathrm{~km}$ for temperature. The vertical resolution of temperature

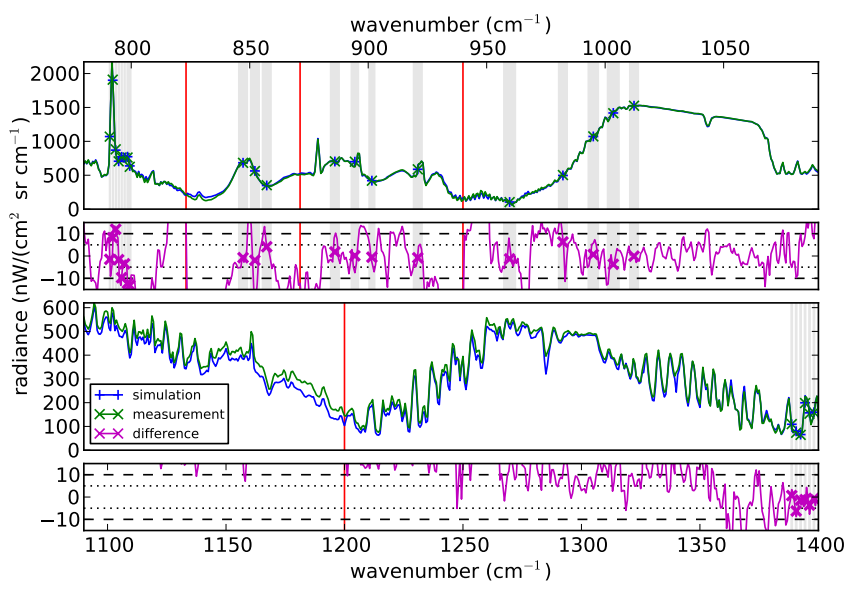

Figure 3. A measured and a simulated dynamics mode spectrum averaged over row 57 (tangent altitude $12.78 \mathrm{~km}$ ) of the detector taken at 14:40:12 UTC and $14.45 \mathrm{~km}$ aircraft altitude. The spectrum is split at $1090 \mathrm{~cm}^{-1}$ with the lower panels showing higher wavenumbers. The lines shows the full spectral resolution of the spectra while the markers show the values of the ISWs used in the retrieval. The extent of the ISWs is overlayed as grey bars. The difference plots also contain the target (dots) and threshold (dashes) values for noise. The vertical red lines separate regions that employ different aerosol/extinction profiles. This simulation was performed using the band model. The large discrepancy in the lower panels is caused by $\mathrm{N}_{2} \mathrm{O}$ and $\mathrm{CH}_{4}$, which are currently not retrieval targets.

will likely increase, if the $\mathrm{CO}_{2}$ Q-branch can be measured to higher precision in the future. The vertical resolution seems to improve again for the lowest altitudes. This is technically correct, but misleading as the shape of the averaging kernels takes on a rather broad base and also partly negative values at lower altitudes. The last two panels of Fig. 5 show the horizontal resolution and displacement. The horizontal resolution along the line of sight of retrieved trace gases is on the order of $100 \mathrm{~km}$. The small horizontal displacement for the trace gases asserts that indeed the trace gas VMRs close to the tangent point (the reference point for the displacement) are being retrieved. But the 2-D averaging kernels of temperature are shown to be biased towards the instrument location, presumably because the ISWs used to determine the temperature are not optically thin. This discrepancy is another error source introduced by the assumption of horizontal homogeneity. However, we expect that the effect is mitigated by the application of ECMWF temperature gradients.

The retrieval results for the primary targets are collected in Fig. 6. Shown is a highly variable structure consisting of many small scale filaments. Anomalies in $\mathrm{O}_{3}$ and $\mathrm{HNO}_{3}$ are mostly well correlated with each other and anti-correlated with $\mathrm{H}_{2} \mathrm{O}$ anomalies. This is expected due to the typical chemical composition of stratospheric air (dry, $\mathrm{O}_{3}$ and $\mathrm{HNO}_{3}$ rich air) and tropospheric air (wet and deprived of $\mathrm{O}_{3}$ and $\mathrm{HNO}_{3}$ ) and makes the observed filamentary structure plausible. From the given figures, one can directly identify air 

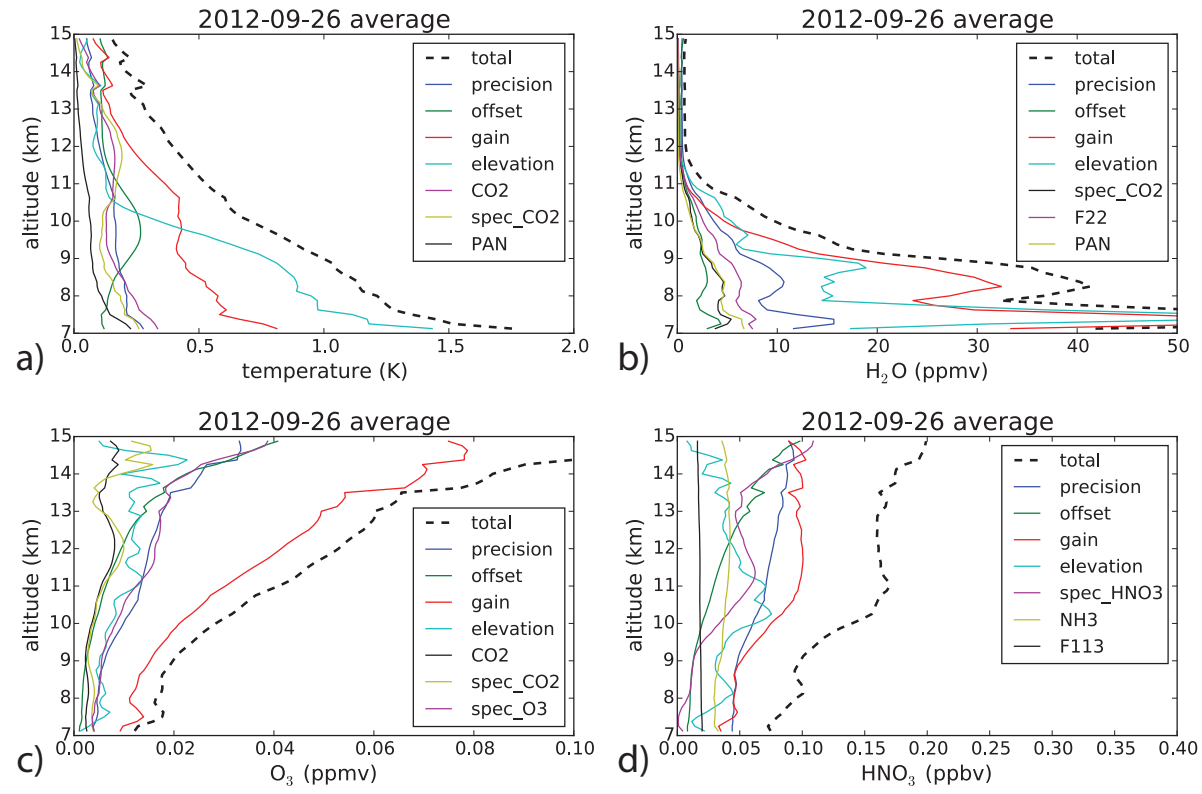

Figure 4. Total error and major error sources for the four primary targets temperature (a), $\mathrm{H}_{2} \mathrm{O}(\mathbf{b}), \mathrm{O}_{3}$ (c), and $\mathrm{HNO}_{3}$ (d) averaged over the profiles of the flight of 26 September 2012. A "spec" prefix notes the error induced by spectral uncertainty of line intensities.
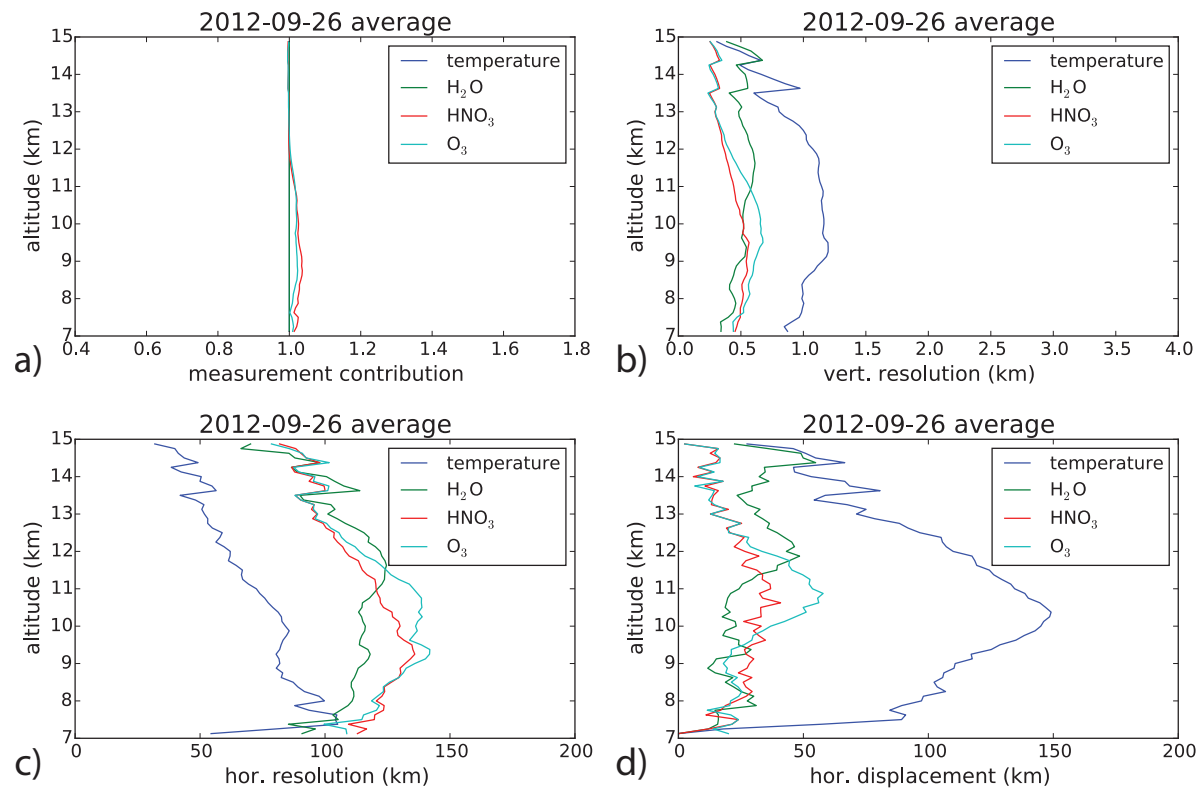

Figure 5. Diagnostic quantities for the four primary targets averaged over the profiles of the flight of 26 September 2012 : measurement contribution (a), vertical resolution (b), horizontal resolution (c), and horizontal displacement (d). Horizontal resolution and displacement have been computed using the band model; displacement is measured relative to the tangent point location. The resolution is defined as the "full width at half max" of the corresponding row of the averaging kernel matrix.

masses, which were recently mixed from the troposphere into the stratosphere like the filament of comparatively wet air at $12 \mathrm{~km}$ around 10:00 UTC.

\subsection{Validation}

The best opportunity for validation is offered by data acquired from other instruments carried aboard HALO. Satellite data are not as useful here, as the given altitude region is usually only coarsely resolved (if at all) and profiles are spa- 

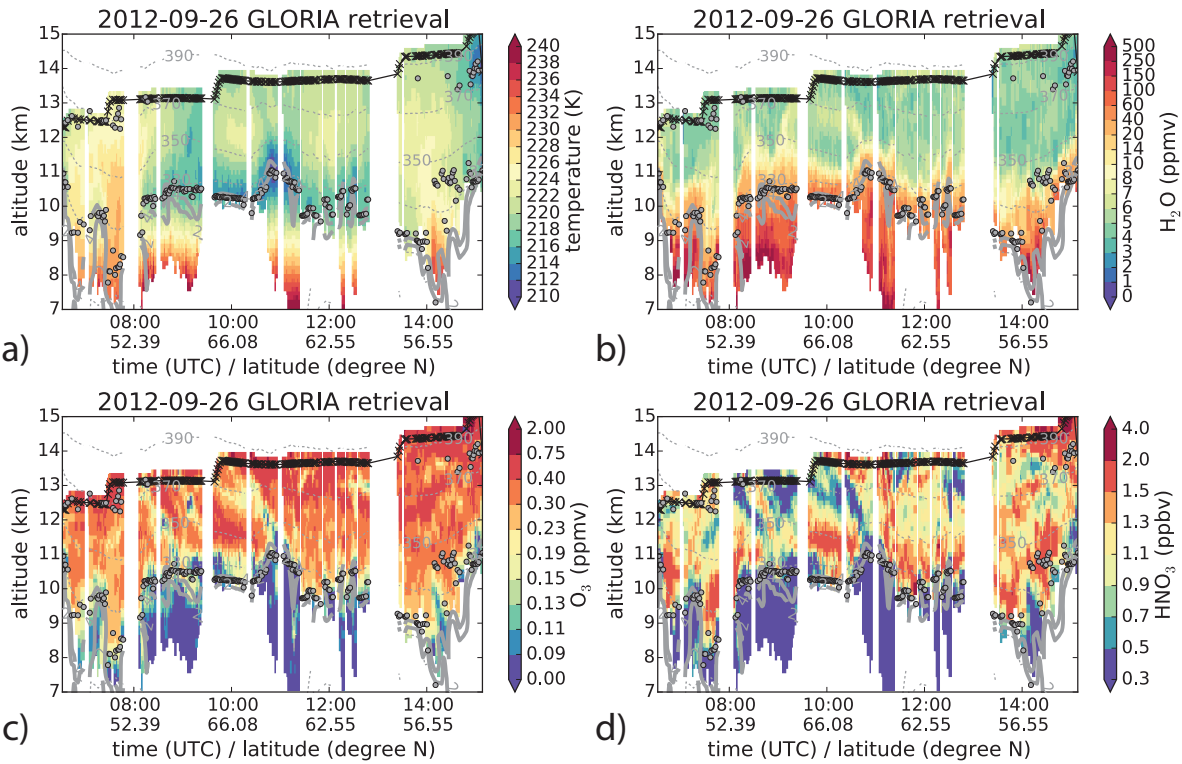

Figure 6. Cross-sections of retrieved quantities for the flight of 26 September 2012: temperature (a), $\mathrm{H}_{2} \mathrm{O}$ (b), $\mathrm{O}_{3}$ (c), and $\mathrm{HNO}_{3}$ (d). $\mathrm{In}$ addition, selected isentropes are shown as dotted grey lines, ECMWF potential vorticity (interpolated to the time of measurement) isolines of 2 and 4 PVU are shown as thick grey lines. The thermal tropopause is derived from retrieved temperature profiles and is shown as thick grey dots. Depicted retrieved values are limited below by clouds and above by the flight altitude.

tially and temporally difficult to align. In the given synoptic situation with strong horizontal temperature gradients, also comparing to radiosonde data is difficult due to the sparsity of radiosonde ascents. This leaves the in situ instruments as the best source for validation. Due to the crowded airspace over Oberpfaffenhofen, it was not possible to directly measure with GLORIA the ascent or descent profiles acquired by the in situ instruments. There are measurements of the dive over Norway available, but this situation was selected specifically for its large horizontal variability, implying a large sampling uncertainty due to the averaging nature of 1-D retrievals. The dive will prove valuable for the characterisation of 3-D tomographic retrievals, though, as it is at the centre of a tomographic hexagonal flight pattern.

Comparing the retrieved temperatures (in fact $125 \mathrm{~m}$ below flight level to mitigate the effect of the top column) against the in situ measurements at flight level is illustrated in Fig. 7. The temperature in Fig. 7a follows closely the measurements, which for this flight agrees also well with ECMWF. Temperatures seem to follow the lower bound of the in situ envelope, which might indicate a low bias (the mean difference is $-0.48 \mathrm{~K}$, see Table 5); the most likely explanation on the GLORIA side for such a bias would be an imperfection in the calibration of the instrument gain. The correlation of all retrieved values at flight levels for the three processed flights is shown in Fig. 7b. The agreement is within expectation for all flights.

Water vapour agrees within error bars to the FISH measurements as shown in Fig. 8a. There seems to be a high bias on the order of $1 \mathrm{ppm}$ (roughly 20\%) after 09:00, which is according to simulations employing fixed ECMWF temperatures related to the low bias in temperature in the same time frame. Another known systematic error source is the use of a standard Voigt line-shape for simulation. Boone et al. (2007) and Schneider et al. (2011) suggest that improved results can be achieved using a speed-dependent Voigt profile. The mean difference for these flights is in the same order but of opposite sign, indicating no consistent systematic problem. The correlation for all processed flights in Fig. 8b shows good agreement. The correlation for the Antarctic flight is lower than for the other flights as the air was very dry and no VMRs above $6 \mathrm{ppm}$ were measured (see also Rolf et al., 2014).

$\mathrm{O}_{3}$ values vary to a much larger degree along the flight path than temperature or $\mathrm{H}_{2} \mathrm{O}$. Figure 9a shows that the retrieval results follow the in situ measurements within given error bars with only few exceptions. These are most likely caused by differences in the measured air masses. Figure $9 b$ shows that the correlation is worse than for temperature and $\mathrm{H}_{2} \mathrm{O}$, which may be due to the higher variability of $\mathrm{O}_{3}$ on small spatial scales.

Further, a comparison for $\mathrm{HNO}_{3}$ is given in Fig. 10a. Similarly to $\mathrm{O}_{3}$, the $\mathrm{HNO}_{3}$ observations cover a large dynamic range. The retrieval results follow the observed dynamic structures closely, even though there are intervals of systematic deviations to the in situ measurements on the order of $\pm 40 \%$. These deviations may be caused by horizontal gradients of trace gas VMRs along the line of sight or - to a lesser extent - also vertical gradients. The correlation for the Antarctic flight in Fig. 10b is lower due to a small num- 

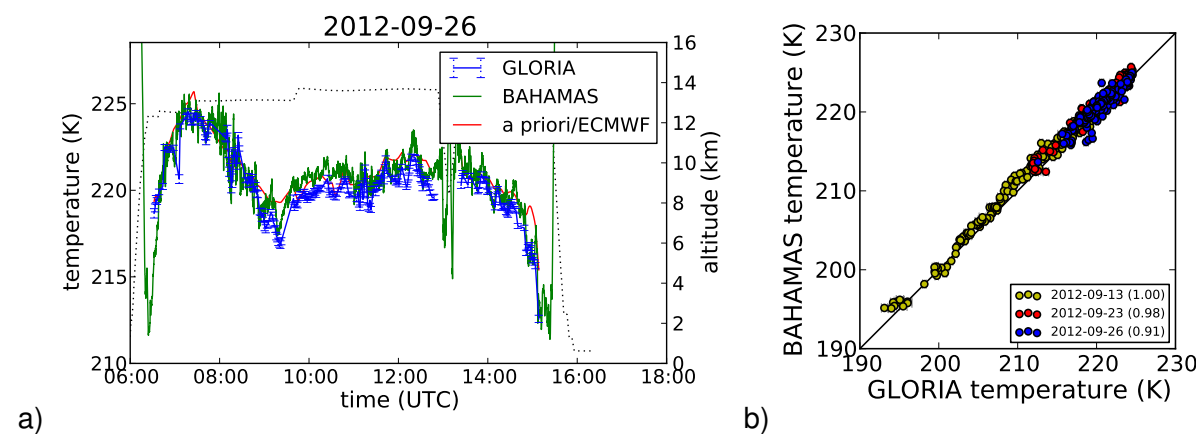

b)

Figure 7. Comparison of retrieved temperature $125 \mathrm{~m}$ below flight level and temperature measured by the HALO BAHAMAS system. The error bars of retrieved values use the total error (accuracy plus precision). (a) shows the values over time for the flight of 26 September 2012 ; in addition the a priori information employed with assumed uncertainty and flight altitude is given. (b) shows the correlation for the three currently processed flights; the Pearson correlation coefficient for the flights is given in the legend. See also Table 5.

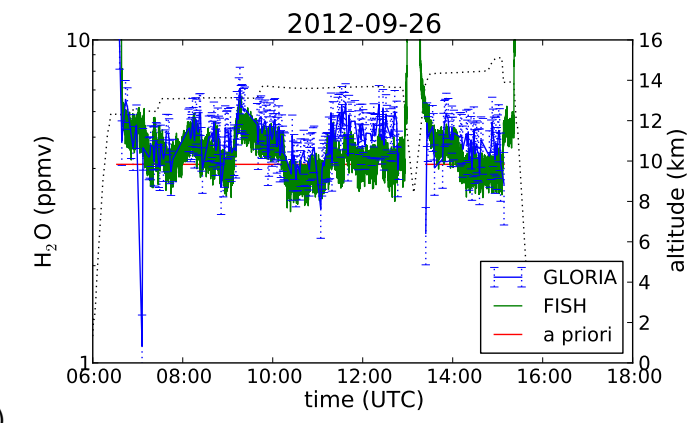

b)

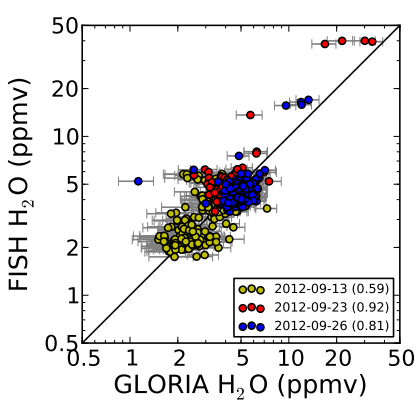

Figure 8. Comparison of retrieved $\mathrm{H}_{2} \mathrm{O} 125 \mathrm{~m}$ below flight level and $\mathrm{H}_{2} \mathrm{O}$ measured by FISH. See also Fig. 7 and Table 5 .

Table 5. Comparison of retrieved targets $125 \mathrm{~m}$ below flight level and quantities measured by in situ instruments (BAHAMAS, Fairo, FISH, and AIMS). Shown are the mean difference and the SD. The last column shows the Pearson correlation coefficient for the linear correlation between retrieved and in situ measured values.

\begin{tabular}{llrrrr}
\hline target & flight & count & bias & stddev & corr \\
\hline temperature (K) & 13 Sep 2012 & 256 & -0.82 & 0.64 & 1.00 \\
& 23 Sep 2012 & 238 & -0.68 & 0.51 & 0.98 \\
& 26 Sep 2012 & 234 & -0.48 & 0.78 & 0.91 \\
\hline $\mathrm{H}_{2} \mathrm{O}$ (ppmv) & 13 Sep 2012 & 230 & -0.15 & 0.93 & 0.59 \\
& 23 Sep 2012 & 222 & -0.30 & 2.27 & 0.92 \\
& 26 Sep 2012 & 195 & 0.41 & 1.08 & 0.81 \\
\hline $\mathrm{O}_{3}$ (ppbv) & 13 Sep 2012 & 181 & -0.02 & 0.14 & 0.66 \\
& 23 Sep 2012 & 158 & -0.02 & 0.09 & 0.56 \\
& 26 Sep 2012 & 140 & 0.06 & 0.11 & 0.69 \\
\hline $\mathrm{HNO}_{3}$ (ppbv) & 13 Sep 2012 & 193 & -0.08 & 0.93 & 0.58 \\
& 23 Sep 2012 & \multicolumn{4}{c}{- not available -} \\
& 26 Sep 2012 & 159 & 0.05 & 0.40 & 0.71 \\
\hline
\end{tabular}

ber of consecutive samples where AIMS measured approximately twice as much $\mathrm{HNO}_{3}$ as GLORIA. In the same profiles, the $\mathrm{O}_{3}$ VMR detected by the in situ instrument Fairo is higher than that derived from GLORIA measurements, hence a very likely explanation is that simply different air masses were measured in the Antarctic polar stratosphere.

The correlation between in situ measurements and GLORIA retrieval results is astonishingly low compared to the visual agreement. It is obvious that the GLORIA limb sounder does not measure the radiance emitted at the location of the aircraft, but rather the radiance emitted by an elongated volume around the tangent point. It was found for previous aircraft campaigns that the limb-sounder measurements often lead or lagged behind the in situ measurements as filaments were slanted toward the flight path and were therefore measured earlier or later by the limb sounder than by the in situ instrument (e.g. Ungermann et al., 2012). It is plausible that most anomalies in measured trace gases form elongated filaments that are not fully orthogonal to the flight path.

To estimate the effect of a lag on the correlation, the autocorrelation of in situ data at GLORIA temporal resolution was determined and a time lag of only $300 \mathrm{~s}$ reduces the correlation from 1 to about 0.75 (whereby temperature was less affected and $\mathrm{H}_{2} \mathrm{O}$ more). This corresponds to a distance of about $50 \mathrm{~km}$ for typical speeds of HALO, which corresponds roughly to twice the horizontal distance between aircraft and the centre of maximum retrieval sensitivity at flight level (see above). The sampling of different air masses may thereby reduce the correlation by up to $\approx 0.25$. Tomographic retrievals 

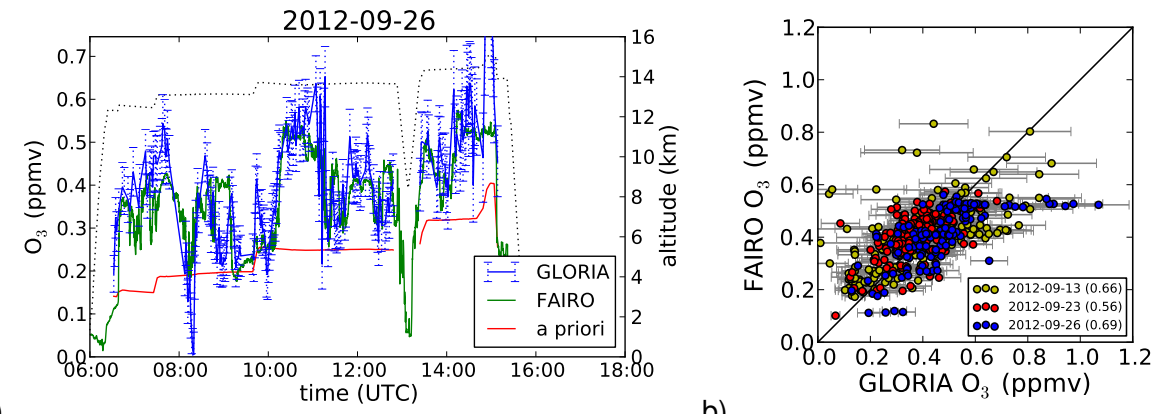

a)

b)

Figure 9. Comparison of retrieved $\mathrm{O}_{3} 125 \mathrm{~m}$ below flight level and $\mathrm{O}_{3}$ measured by Fairo. See also Fig. 7 and Table 5.
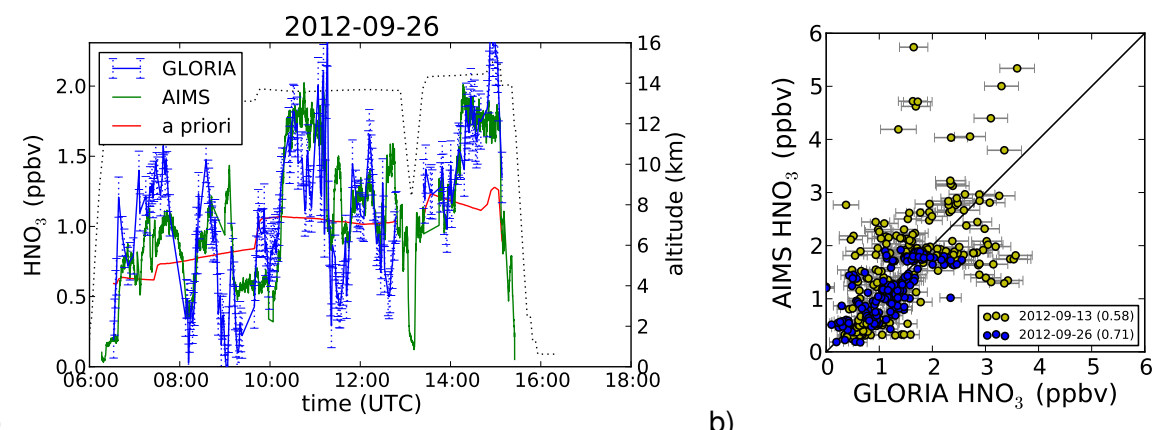

a)

b)

Figure 10. Comparison of retrieved $\mathrm{HNO}_{3} 125 \mathrm{~m}$ below flight level and $\mathrm{HNO}_{3}$ measured by AIMS. See also Fig. 7 and Table 5. On 23 September 2012, AIMS has been operated in the water vapour mode; therefore no $\mathrm{HNO}_{3}$ data are available for that flight.

are not subject to such an effect and should deliver more consistent results.

\section{Conclusions}

GLORIA in its present state allows the successful retrieval of several key species and parameters for examining the structure and composition of the highly dynamic UTLS region. The primary targets contain a primarily tropospheric tracer $\left(\mathrm{H}_{2} \mathrm{O}\right)$, a primarily stratospheric tracer $\left(\mathrm{O}_{3}\right)$, and with a highly resolved temperature product also a quantity to closely examine the thermal tropopause. The vertical resolution of 250 to $500 \mathrm{~m}$ achieved by GLORIA is a further improvement over the already highly resolved CRISTA-NF airborne limb sounder and offers an unprecedented view upon the UTLS. It is expected that the vertical resolution of temperature can be further improved when the instrument artefacts around the $\mathrm{CO}_{2}$ Q-branch have been resolved. The agreement with in situ data is generally good and within range of estimated errors. Discrepancies in correlation can be partially explained by the differences in viewing geometry and a resulting time-varying lag between the compared instruments.

The results of the last flight on 26 September 2012 demonstrate the Rossby-wave driven intricate structure of the UTLS during summer over Europe that was also observed during previous campaigns (Ungermann et al., 2013). Future work will expand on this data set by evaluating the remaining TACTS and ESMVal flights after the final level 1 data set is generated for the complete campaign. This paper also provides the basis for the evaluation of upcoming campaigns, which should be even more straightforward due to the increased experience with operating the GLORIA instrument.

As has been shown by Kaufmann et al. (2015), one of the major advantages of GLORIA is the capability to use tomographic techniques to create a 3-D reproduction of atmospheric structure, unaffected by artefacts produced by the assumption of horizontal homogeneity of 1-D retrievals. The current setup provides a sound basis for the tomographic processing of hexagonal and also linear flight patterns. This will allow exploitation of the full set of GLORIA measurements taken in the dynamics mode.

Acknowledgements. We thank all members of the GLORIA instrument team for their large efforts in developing the first IR limb imager. The GLORIA hardware was mainly funded by the Helmholtz Association of German Research Centres through several large investment funds. We sincerely thank A. Dudhia, Oxford University, for providing the Reference Forward Model (RFM) used to calculate the optical path and extinction cross-section tables required by our forward models. We also wish to thank L. Hoffmann, who developed the predecessor of JURASSIC2. D. E. Kinnision, NCAR, is thanked for kindly 
providing the WACCM4 model data used in the retrieval. The European Centre for Medium-Range Weather Forecasts (ECMWF) is acknowledged for meteorological data support. The operational implementation of the first tomographic flights was supported by $\mathrm{H}$. Bönisch and A. Engel, who coordinated TACTS. We also gratefully acknowledge the funding of the ESMVal flight hours by DLR and the coordination of ESMVal by H. Schlager. GLORIA retrieval activities were supported under the DFG project RASGLO (HALO-SPP 1294/Ka 2324/1-2) and flight planning by CLaMS model forecasts under the DFG project LASSO (HALO- SPP 1294/GR 3786).

The article processing charges for this open-access publication were covered by a Research

Centre of the Helmholtz Association.

Edited by: C. von Savigny

\section{References}

Bange, J., Esposito, M., Lenschow, D. H., Brown, P. R. A., Dreiling, V., Giez, A., Mahrt, L., Malinowski, S. P., Rodi, A. R., Shaw, R. A., Siebert, H., Smit, H., and Zöger, M.: Measurement of aircraft state and thermodynamic and dynamic variables, in: Airborne Measurements for Environmental Research: Methods and Instruments, edited by: Wendisch, M., and Brenguier, J.-L., Wiley-VCH Verlag GmbH \& Co. KGaA, Weinheim, Germany, 7-75, doi:10.1002/9783527653218.ch2, 2013.

Berthet, G., Esler, J. G., and Haynes, P. H.: A Lagrangian perspective of the tropopause and the ventilation of the lowermost stratosphere, J. Geophys. Res., 112, D18102, doi:10.1029/2006JD008295, 2007.

Birner, T.: Fine-scale structure of the extratropical tropopause region, J. Geophys. Res., 111, D04104, doi:10.1029/2005JD006301, 2006.

Blank, J.: Tomographic Retrieval of Atmospheric Trace Gases Observed by GLORIA, Forschungszentrum Jülich, Jülich, $\mathrm{PhD}$ thesis, Wuppertal University, 2013.

Boone, C. D., Walker, K. A., and Bernath, P. F.: Speeddependent Voigt profile for water vapor in infrared remote sensing applications, J. Quant. Spectrosc. Ra., 105, 525-532, doi:10.1016/j.jqsrt.2006.11.015, 2007.

Chen, P.: Isentropic cross-tropopause mass exchange in the extratropics, J. Geophys. Res., 100, 16661-16673, doi:10.1029/95JD01264, 1995.

Curtis, A. R.: Discussion of "A statistical model for water vapour absorption” by R. M. Goody, Q. J. Roy. Meteor. Soc., 78, 638640, 1952.

Dudhia, A., Morris, P. E., and Wells, R. J.: Fast monochromatic radiative transfer calculations for limb sounding, J. Quant. Spectrosc. Ra., 74, 745-756, doi:10.1016/S0022-4073(01)00285-0, 2002.

Fahey, D. W., Gao, R.-S., Möhler, O., Saathoff, H., Schiller, C., Ebert, V., Krämer, M., Peter, T., Amarouche, N., Avallone, L. M., Bauer, R., Bozóki, Z., Christensen, L. E., Davis, S. M., Durry, G., Dyroff, C., Herman, R. L., Hunsmann, S., Khaykin, S. M., Mackrodt, P., Meyer, J., Smith, J. B., Spelten, N., Troy, R. F., Vömel, H., Wagner, S., and Wienhold, F. G.: The AquaVIT-1 intercom- parison of atmospheric water vapor measurement techniques, Atmos. Meas. Tech., 7, 3177-3213, doi:10.5194/amt-7-3177-2014, 2014.

Fischer, H., Birk, M., Blom, C., Carli, B., Carlotti, M., von Clarmann, T., Delbouille, L., Dudhia, A., Ehhalt, D., Endemann, M., Flaud, J. M., Gessner, R., Kleinert, A., Koopman, R., Langen, J., López-Puertas, M., Mosner, P., Nett, H., Oelhaf, H., Perron, G., Remedios, J., Ridolfi, M., Stiller, G., and Zander, R.: MIPAS: an instrument for atmospheric and climate research, Atmos. Chem. Phys., 8, 2151-2188, doi:10.5194/acp-8-2151-2008, 2008.

Francis, G. L., Edwards, D. P., Lambert, A., Halvorson, C. M., Lee-Taylor, J. M., and Gille, J. C.: Forward modeling and radiative transfer for the NASA EOS-Aura High Resolution Dynamics Limb Sounder (HIRDLS) instrument, J. Geophys. Res., 111, D13301, doi:10.1029/2005JD006270, 2006.

Friedl-Vallon, F., Riese, M., Maucher, G., Lengel, A., Hase, F., Preusse, P., and Spang, R.: Instrument concept and preliminary performance analysis of GLORIA, Adv. Space Res., 37, 22872291, doi:10.1016/j.asr.2005.07.075, 2006.

Friedl-Vallon, F., Gulde, T., Hase, F., Kleinert, A., Kulessa, T., Maucher, G., Neubert, T., Olschewski, F., Piesch, C., Preusse, P., Rongen, H., Sartorius, C., Schneider, H., Schönfeld, A., Tan, V., Bayer, N., Blank, J., Dapp, R., Ebersoldt, A., Fischer, H., Graf, F., Guggenmoser, T., Höpfner, M., Kaufmann, M., Kretschmer, E., Latzko, T., Nordmeyer, H., Oelhaf, H., Orphal, J., Riese, M., Schardt, G., Schillings, J., Sha, M. K., Suminska-Ebersoldt, O., and Ungermann, J.: Instrument concept of the imaging Fourier transform spectrometer GLORIA, Atmos. Meas. Tech., 7, 35653577, doi:10.5194/amt-7-3565-2014, 2014.

Garcia, R. R., Marsh, D., Kinnison, D. E., Boville, B., and Sassi, F.: Simulations of secular trends in the middle atmosphere 1950-2003, J. Geophys. Res., 112, D09301, doi:10.1029/2006JD007485, 2007.

Giez, A.: Effective test and calibration of a trailing cone system on the atmospheric research aircraft HALO, in: Proceedings of the 56th Annual Symposium of the Society of Experimental Test Pilots, Anaheim, USA, 35-46, 2012.

Gille, J. C., Barnett, J., Arter, P., Barker, M., Bernath, P., Boone, C., Cavanaugh, C., Chow, J., Coffey, M., Craft, J., Craig, C., Dials, M., Dean, V., Eden, T., Edwards, D. P., Francis, G., Halvorson, C., Harvey, L., Hepplewhite, C., Khosravi, R., Kinnison, D., Krinsky, C., Lambert, A., Lee, H., Lyjak, L., Loh, J., Mankin, W., Massie, S., McInerney, J., Moorhouse, J., Nardi, B., Packman, D., Randall, C., Reburn, J., Rudolf, W., Schwartz, M., Serafin, J., Stone, K., Torpy, B., Walker, K., Waterfall, A., Watkins, R., Whitney, J., Woodard, D., and Young, G.: The highresolution dynamics limb sounder: experiment overview, recovery, and validation of initial temperature data, J. Geophys. Res., 113, D16S43, doi:10.1029/2007JD008824, 2008.

Gille, J., Karol, S., Kinnison, D., Lamarque, J.-F., and Yudin, V.: The role of midlatitude mixing barriers in creating the annual variation of total ozone in high northern latitudes, J. Geophys. Res., 119, 9578-9595, doi:10.1002/2013JD021416, 2014.

Glatthor, N., von Clarmann, T., Fischer, H., Funke, B., Grabowski, U., Höpfner, M., Kellmann, S., Kiefer, M., Linden, A., Milz, M., Steck, T., and Stiller, G. P.: Global peroxyacetyl nitrate (PAN) retrieval in the upper troposphere from limb emission spectra of the Michelson Interferometer for Passive Atmospheric Sounding 
(MIPAS), Atmos. Chem. Phys., 7, 2775-2787, doi:10.5194/acp7-2775-2007, 2007.

Godson, W. L.: The evaluation of infra-red radiative fluxes due to atmospheric water vapour, Q. J. Roy. Meteor. Soc., 79, 367-379, 1953.

Gordley, L. L. and Russell, J. M.: Rapid inversion of limb radiance data using an emissivity growth approximation, Appl. Optics, 20, 807-813, doi:10.1364/AO.20.000807, 1981.

Griessbach, S., Hoffmann, L., Höpfner, M., Riese, M., and Spang, R.: Scattering in infrared radiative transfer: a comparison between the spectrally averaging model JURASSIC and the lineby-line model KOPRA, J. Quant. Spectrosc. Ra., 127, 102-118, doi:10.1016/j.jqsrt.2013.05.004, 2013.

Guggenmoser, T., Blank, J., Kleinert, A., Latzko, T., Ungermann, J., Friedl-Vallon, F., Höpfner, M., Kaufmann, M., Kretschmer, E., Maucher, G., Neubert, T., Oelhaf, H., Preusse, P., Riese, M., Rongen, H., K. Sha, M., Sumin'ska-Ebersoldt, O., and Tan, V.: New calibration noise suppression techniques for the GLORIA limb imager, Atmos. Meas. Tech. Discuss., 7, 12649-12689, doi:10.5194/amtd-7-12649-2014, 2014.

HALO database: available at: https://halo-db.pa.op.dlr.de/, last access: 1 December 2014.

Hase, F. and Höpfner, M.: Atmospheric ray path modeling for radiative transfer algorithms, Appl. Optics, 38, 3129-3133, doi:10.1364/AO.38.003129, 1999.

Haynes, P. and Shuckburgh, E.: Effective diffusivity as a diagnostic of atmospheric transport: 1. Stratosphere, J. Geophys. Res., 105, 22777-22794, doi:10.1029/2000JD900093, 2000.

Hegglin, M. I., Boone, C. D., Manney, G. L., and Walker, K. A.: A global view of the extratropical tropopause transition layer from Atmospheric Chemistry Experiment Fourier Transform Spectrometer $\mathrm{O}_{3}, \mathrm{H}_{2} \mathrm{O}$, and $\mathrm{CO}$, J. Geophys. Res., 114, D00B11, doi:10.1029/2008JD009984, 2009.

Hoffmann, L. and Alexander, M. J.: Retrieval of stratospheric temperatures from Atmospheric Infrared Sounder radiance measurements for gravity wave studies, J. Geophys. Res., 114, D07105, doi:10.1029/2008JD011241, 2009.

Jurkat, T., Voigt, C., Arnold, F., Schlager, H., Aufmhoff, H., Schmale, J., Schneider, J., Lichtenstern, M., and Dörnbrack, A.: Airborne stratospheric ITCIMS-measurements of $\mathrm{SO}_{2}, \mathrm{HCl}$, and $\mathrm{HNO}_{3}$ in the aged plume of volcano Kasatochi, J. Geophys. Res., 115, D00L17, doi:10.1029/2010JD013890, 2010.

Jurkat, T., Voigt, C., Kaufmann, S., Zahn, A., Sprenger, A. M., Hoor, P., Bozem, H., Müller, S., Dörnbrack, A., Schlager, H., Bönisch, H., and Engel, A.: A quantitative analysis of stratospheric $\mathrm{HCl}, \mathrm{HNO}_{3}$, and $\mathrm{O}_{3}$ in the tropopause region near the subtropical jet, Geophys. Res. Lett., 41, 3315-3321, doi:10.1002/2013GL059159, 2014.

Kaufmann, M., Blank, J., Friedl-Vallon, F., Gerber, D., Guggenmoser, T., Höpfner, M., Kleinert, A., Sha, M. K., Oelhaf, H., Riese, M., Suminska-Ebersoldt, O., Woiwode, W., Siddans, R., Kerridge, B., Moyna, B., Rea, S., and Oldfield, M.: Technical Assistance for the Deployment of Airborne Limbsounders During ESSenCe, Tech. rep., European Space Agency, 2013.

Kaufmann, S., Voigt, C., Jeßberger, P., Jurkat, T., Schlager, H., Schwarzenboeck, A., Klingebiel, M., and Thornberry, T.: In situ measurements of ice saturation in young contrails, Geophys. Res. Lett., 41, 702-709, doi:10.1002/2013GL058276, 2014.
Kaufmann, M., Blank, J., Guggenmoser, T., Ungermann, J., Engel, A., Ern, M., Friedl-Vallon, F., Gerber, D., Grooß, J. U., Guenther, G., Höpfner, M., Kleinert, A., Kretschmer, E., Latzko, Th., Maucher, G., Neubert, T., Nordmeyer, H., Oelhaf, H., Olschewski, F., Orphal, J., Preusse, P., Schlager, H., Schneider, H., Schuettemeyer, D., Stroh, F., Suminska-Ebersoldt, O., Vogel, B., M. Volk, C., Woiwode, W., and Riese, M.: Retrieval of threedimensional small-scale structures in upper-tropospheric/lowerstratospheric composition as measured by GLORIA, Atmos. Meas. Tech., 8, 81-95, doi:10.5194/amt-8-81-2015, 2015.

Kleinert, A., Friedl-Vallon, F., Guggenmoser, T., Höpfner, M., Neubert, T., Ribalda, R., Sha, M. K., Ungermann, J., Blank, J., Ebersoldt, A., Kretschmer, E., Latzko, T., Oelhaf, H., Olschewski, F., and Preusse, P.: Level 0 to 1 processing of the imaging Fourier transform spectrometer GLORIA: generation of radiometrically and spectrally calibrated spectra, Atmos. Meas. Tech., 7, 41674184, doi:10.5194/amt-7-4167-2014, 2014.

Krautstrunk, M. and Giez, A.: The Transition from FALCON to HALO era airborne atmospheric research, in: Atmospheric Physics, edited by: Schumann, U., Research Topics in Aerospace, Springer Verlag, Berlin, 609-624, doi:10.1007/9783-642-30183-4_37, 2012.

Kunz, A., Pan, L. L., Konopka, P., Kinnison, D., and Tilmes, S.: Chemical and dynamical discontinuity at the extratropical tropopause based on START08 and WACCM analysis, J. Geophys. Res., 116, D24302, doi:10.1029/2011JD016686, 2011.

Lamarque, J.-F., Emmons, L. K., Hess, P. G., Kinnison, D. E., Tilmes, S., Vitt, F., Heald, C. L., Holland, E. A., Lauritzen, P. H., Neu, J., Orlando, J. J., Rasch, P. J., and Tyndall, G. K.: CAM-chem: description and evaluation of interactive atmospheric chemistry in the Community Earth System Model, Geosci. Model Dev., 5, 369-411, doi:10.5194/gmd-5-369-2012, 2012.

Lotz, J., Naumann, U., and Ungermann, J.: Hierarchical Algorithmic Differentiation - A Case Study, in: Recent Advances in Algorithmic Differentiation, edited by: Forth, S., Hovland, P., Phipps, E., Utke, J., and Walther, A., Lecture Notes in Computational Science and Engineering, Springer, 87, 187-196, doi:10.1007/978-3-642-30023-3_17, 2012.

Marshall, B. T., Gordley, L. L., and Chu, D. A.: BANDPAK: algorithms for modeling broadband transmission and radiance, J. Quant. Spectrosc. Ra., 52, 581-599, doi:10.1016/00224073(94)90026-4, 1994.

Mlawer, E. J., Payne, V. H., Moncet, J.-L., Delamere, J. S., Alvarado, M. J., and Tobin, D. D.: Development and recent evaluation of the MT_CKD model of continuum absorption, Philos. T. Roy. Soc. A, 370, 1-37, doi:10.1098/rsta.2011.0295, 2012.

Nakamura, N.: Two-dimensional mixing, edge formation, and permeability diagnosed in area coordinates, J. Atmos. Sci., 53, 1524-1537, 1996.

Offermann, D., Grossmann, K.-U., Barthol, P., Knieling, P., Riese, M., and Trant, R.: Cryogenic infrared spectrometers and telescopes for the atmosphere (CRISTA) experiment and middle atmosphere variability, J. Geophys. Res., 104, 16311-16325, doi:10.1029/1998JD100047, 1999.

Peevey, T. R., Gille, J. C., Homeyer, C. R., and Manney, G. L.: The double tropopause and its dynamical relationship to the tropopause inversion layer in storm track regions, J. Geophys. Res., 119, doi:10.1002/2014JD021808, 2014. 
Postel, G. A. and Hitchman, M. H.: A climatology of Rossby wave breaking along the subtropical tropopause, J. Atmos. Sci., 56, 359-373, doi:10.1175/15200469(1999)056<0359:ACORWB>2.0.CO;2, 1999.

Remedios, J. J., Leigh, R. J., Waterfall, A. M., Moore, D. P., Sembhi, H., Parkes, I., Greenhough, J., Chipperfield, M.P., and Hauglustaine, D.: MIPAS reference atmospheres and comparisons to V4.61/V4.62 MIPAS level 2 geophysical data sets, Atmos. Chem. Phys. Discuss., 7, 9973-10017, doi:10.5194/acpd-79973-2007, 2007.

Riese, M., Friedl-Vallon, F., Spang, R., Preusse, P., Schiller, C., Hoffmann, L., Konopka, P., Oelhaf, H., von Clarmann, T., and Höpfner, M.: GLObal limb radiance imager for the atmosphere (GLORIA): scientific objectives, Adv. Space Res., 36, 989-995, doi:10.1016/j.asr.2005.04.115, 2005.

Riese, M., Ploeger, F., Rap, A., Vogel, B., Konopka, P., Dameris, M., and Forster, P.: Impact of uncertainties in atmospheric mixing on simulated UTLS composition and related radiative effects, J. Geophys. Res., 117, D16305, doi:10.1029/2012JD017751, 2012.

Riese, M., Oelhaf, H., Preusse, P., Blank, J., Ern, M., Friedl-Vallon, F., Fischer, H., Guggenmoser, T., Höpfner, M., Hoor, P., Kaufmann, M., Orphal, J., Plöger, F., Spang, R., Suminska-Ebersoldt, O., Ungermann, J., Vogel, B., and Woiwode, W.: Gimballed Limb Observer for Radiance Imaging of the Atmosphere (GLORIA) scientific objectives, Atmos. Meas. Tech., 7, 1915-1928, doi:10.5194/amt-7-1915-2014, 2014.

Rodgers, C. D.: Inverse Methods for Atmospheric Sounding: Theory and Practice, Vol. 2 of Series on Atmospheric, Oceanic and Planetary Physics, World Scientific, Singapore, 2000.

Rolf, C., Afchine, A., Bozem, H., Buchholz, B., Ebert, V., Guggenmoser, T., Hoor, P., Konopka, P., Kretschmer, E., Müller, S., Schlager, H., Spelten, N., Sumin'ska-Ebersoldt, O., Ungermann, J., Zahn, A., and Krämer, M.: Transport of Antarctic stratospheric strongly dehydrated air into the troposphere observed during the HALO-ESMVal campaign 2012, Atmos. Chem. Phys. Discuss., 15, 7895-7932, doi:10.5194/acpd-157895-2015, 2015.

Rollins, A. W., Thornberry, T. D., Gao, R. S., Smith, J. B., Sayres, D. S., Sargent, M. R., Schiller, C., Kraemer, M., Spelten, N., Hurst, D. F., Jordan, A. F., Hall, E. G., Voemel, H., Diskin, G. S., Podolske, J. R., Christensen, L. E., Rosenlof, K. H., Jensen, E. J., and Fahey, D. W.: Evaluation of UT/LS hygrometer accuracy by intercomparison during the NASA MACPEX mission, J. Geophys. Res., 119, 1915-1935, doi:10.1002/2013JD020817, 2014.

Rothman, L., Gordon, I., Babikov, Y., Barbe, A., Benner, D. C., Bernath, P., Birk, M., Bizzocchi, L., Boudon, V., Brown, L., Campargue, A., Chance, K., Cohen, E., Coudert, L., Devi, V., Drouin, B., Fayt, A., Flaud, J.-M., Gamache, R., Harrison, J., Hartmann, J.-M., Hill, C., Hodges, J., Jacquemart, D., Jolly, A., Lamouroux, J., Roy, R. L., Li, G., Long, D., Lyulin, O., Mackie, C., Massie, S., Mikhailenko, S., Müller, H., Naumenko, O., Nikitin, A., Orphal, J., Perevalov, V., Perrin, A., Polovtseva, E., Richard, C., Smith, M., Starikova, E., Sung, K., Tashkun, S., Tennyson, J., Toon, G., Tyuterev, V., and Wagner, G.: The HITRAN2012 molecular spectroscopic database, J. Quant. Spectrosc. Ra., 130, 4-50, doi:10.1016/j.jqsrt.2013.07.002, HITRAN2012 special issue, 2013.
Schiller, C., Kraemer, M., Afchine, A., Spelten, N., and Sitnikov, N.: Ice water content of Arctic, midlatitude, and tropical cirrus, J. Geophys. Res., 113, D24208, doi:10.1029/2008JD010342, 2008.

Schneider, M., Hase, F., and Blumenstock, T.: Water vapour profiles by ground-based FTIR spectroscopy: study for an optimised retrieval and its validation, Atmos. Chem. Phys., 6, 811-830, doi:10.5194/acp-6-811-2006, 2006.

Schneider, M., Hase, F., Blavier, J.-F., Toon, G. C., and Leblanc, T.: An empirical study on the importance of a speed-dependent Voigt line shape model for tropospheric water vapor profile remote sensing, J. Quant. Spectrosc. Ra., 112, 465-474, doi:10.1016/j.jqsrt.2010.09.008, 2011.

Solomon, S., Qin, D., Manning, M., Alley, R., Berntsen, T., Bindoff, N., Chen, Z., Chidthaisong, A., Gregory, J., Hegerl, G., Heimann, M., Hewitson, B., Hoskins, B., Joos, F., Jouzel, J., Kattsov, V., Lohmann, U., Matsuno, T., Molina, M., Nicholls, N., J.Overpeck, Raga, G., Ramaswamy, V., Ren, J., Rusticucci, M., Somerville, R., Stocker, T., Whetton, P., Wood, R. A., and Wratt, D.: Technical summary, in: Climate Change 2007 - The Physical Science Basis. Contribution of Working Group I to the Fourth Assessment Report of the Intergovernmental Panel on Climate Change, Cambridge University Press, Cambridge, United Kingdom and New York, NY, USA, 2007.

Steck, T. and von Clarmann, T.: Constrained profile retrieval applied to the observation mode of the Michelson Interferometer for Passive Atmospheric Sounding, Appl. Optics, 40, 35593571, doi:10.1364/AO.40.003559, 2001.

Tikhonov, A. N. and Arsenin, V. Y.: Solutions of Ill-Posed Problems, Winston, Washington DC, USA, 1977.

Ungermann, J.: Improving retrieval quality for airborne limb sounders by horizontal regularisation, Atmos. Meas. Tech., 6, 15-32, doi:10.5194/amt-6-15-2013, 2013.

Ungermann, J., Blank, J., Lotz, J., Leppkes, K., Hoffmann, L., Guggenmoser, T., Kaufmann, M., Preusse, P., Naumann, U., and Riese, M.: A 3-D tomographic retrieval approach with advection compensation for the air-borne limb-imager GLORIA, Atmos. Meas. Tech., 4, 2509-2529, doi:10.5194/amt-4-2509-2011, 2011.

Ungermann, J., Kalicinsky, C., Olschewski, F., Knieling, P., Hoffmann, L., Blank, J., Woiwode, W., Oelhaf, H., Hösen, E., Volk, C. M., Ulanovsky, A., Ravegnani, F., Weigel, K., Stroh, F., and Riese, M.: CRISTA-NF measurements with unprecedented vertical resolution during the RECONCILE aircraft campaign, Atmos. Meas. Tech., 5, 1173-1191, doi:10.5194/amt-5-1173-2012, 2012.

Ungermann, J., Pan, L. L., Kalicinsky, C., Olschewski, F., Knieling, P., Blank, J., Weigel, K., Guggenmoser, T., Stroh, F., Hoffmann, L., and Riese, M.: Filamentary structure in chemical tracer distributions near the subtropical jet following a wave breaking event, Atmos. Chem. Phys., 13, 10517-10534, doi:10.5194/acp13-10517-2013, 2013.

Voigt, C., Schumann, U., Jurkat, T., Schäuble, D., Schlager, H., Petzold, A., Gayet, J.-F., Krämer, M., Schneider, J., Borrmann, S., Schmale, J., Jessberger, P., Hamburger, T., Lichtenstern, M., Scheibe, M., Gourbeyre, C., Meyer, J., Kübbeler, M., Frey, W., Kalesse, H., Butler, T., Lawrence, M. G., Holzäpfel, F., Arnold, F., Wendisch, M., Döpelheuer, A., Gottschaldt, K., Baumann, R., 
Zöger, M., Sölch, I., Rautenhaus, M., and Dörnbrack, A.: In-situ observations of young contrails - overview and selected results from the CONCERT campaign, Atmos. Chem. Phys., 10, 90399056, doi:10.5194/acp-10-9039-2010, 2010.

Voigt, C., Jessberger, P., Jurkat, T., Kaufmann, S., Baumann, R., Schlager, H., Bobrowski, N., Guffirda, G., and Salerno, G.: Evolution of $\mathrm{SO}_{2}, \mathrm{HCl}, \mathrm{HNO}_{3}$ and $\mathrm{CO}_{2}$ in the volcanic plume from Etna, Geophys. Res. Lett., 41, 2196-2203, doi:10.1002/2013GL058974, 2014.

von Clarmann, T., De Clercq, C., Ridolfi, M., Höpfner, M., and Lambert, J.-C.: The horizontal resolution of MIPAS, Atmos. Meas. Tech., 2, 47-54, doi:10.5194/amt-2-47-2009, 2009.

Weinreb, M. P. and Neuendorffer, A. C.: Method to apply homogeneous-path transmittance models to inhomogeneous atmospheres, J. Atmos. Sci., 30, 662-666, doi:10.1175/15200469(1973)030<0662:MTAHPT>2.0.CO;2, 1973.
Zahn, A., Weppner, J., Widmann, H., Schlote-Holubek, K., Burger, B., Kühner, T., and Franke, H.: A fast and precise chemiluminescence ozone detector for eddy flux and airborne application, Atmos. Meas. Tech., 5, 363-375, doi:10.5194/amt-5-363-2012, 2012.

Zöger, M., Afchine, A., Eicke, N., Gerhards, M. T., Klein, E., McKenna, D. S., Morschel, U., Schmidt, U., Tan, V., Tuitjer, F., Woyke, T., and Schiller, C.: Fast in situ stratospheric hygrometers: a new family of balloon-borne and airborne Lyman alpha photofragment fluorescence hygrometers, J. Geophys. Res., 104, 1807-1816, doi:10.1029/1998JD100025, 1999. 